\title{
Genetic Polymorphism of the Wild and In vitro Regenerated Plants of the Medicinal Grass Cymbopogon schoenanthus subsp. proximus
}

\author{
Asmaa M. ABDELSALAM ${ }^{1,2}$, Kamal CHOWDHURY², \\ Ahmed A. El-BAKRY ${ }^{1 *}$ \\ ${ }^{1}$ Helwan University, Faculty of Science, Ain Helwan, Cairo 11795, \\ Egypt; asm.abdelsalam@yahoo.com; ael_bakry@yahoo.com (*correspondingauthor) \\ ${ }^{2}$ Claflin University, Biology Department, 400 Magnolia St., Orangeburg, SC 29115, USA; kchowdhury@claflin.edu
}

\begin{abstract}
Cymbopogon schoenanthus subsp. proximus grows wild in subtropical Africa, Sudan and Egypt. The species is heavily collected for its use in folk medicine and drug production. A wild population from south Egypt was used to determine preliminary genetic polymorphism within the species, using nineteen ISSR, fourteen RAPD and seven cpSSR primers. Three regeneration systems, somatic embryogenesis (SE), direct organogenesis (D), and indirect organogenesis (ID), were established from seed explants of the same population and polymorphism within regenerated plants was determined. ISSR generated a total of 222 amplified fragments for all genotypes, while RAPDs and cPSSR yielded 139 and 34 fragments, respectively. Wild plants showed an average low polymorphism for all marker types of $45.8 \%$. Regenerated plants polymorphism was also low $(S E=44.6, D=44, I D=46.2 \%)$. ISSR and cpSSR markers were more sensitive in elucidating polymorphism (51.5 and 46.87\%) than RAPD (37.85\%). ISSR was the most significant marker in producing unique bands, for the wild genotypes (6), SE (7), D (5) and ID (6). cpSSR followed producing 4 for wild genotypes, 6 for SE, 3 for D and 6 for ID organogenesis. Unweighted pair group with arithmetic average (UPGMA) clustering analysis and Jaccard's similarity data suggested that wild plants and those regenerated through somatic embryogenesis and direct organogenesis are more similar. The study elucidated low polymorphism within both the wild population and regenerated genotypes, with plants regenerated through somatic embryogenesis and direct organogenesis being more similar to wild plant genotypes, suggesting their future use in studies with genetic transformation and ex-situ conservation of the species.
\end{abstract}

Keywords: cpSSR; ISSR; organogenesis; RAPD; somatic embryogenesis

\section{Introduction}

Cymbopogon schoenanthus subsp. proximus is a wild aromatic herb that grows in sandy soil under arid climate (Bolous, 1999). Wild plant extract of this subspecies contains compounds that are important for folk medicine and pharmaceutical industry (Bolous, 1983). For example, sesquiterpene proximadiol, a component in the plant oil, has been found to be responsible for repulsion of the renal calculi (Locksley et al., 1982; El-Askary et al., 2003). Other terpenoids were identified in the plant extract (El Taher and Abdel-Kader, 2008). Antimicrobial and antioxidant activities of the plant extract have also been reported (Selim, 2011). NMR metabolic profiling for the species polar extract showed the presence of additional compounds of metabolic, medicinal and economic importance as trehalose, choline and the anticancer alkaloid trigonelline (Abdelsalam et al., 2017a).
In vitro propagation is a valuable method because of its ability to produce true-to-type genotypes in a short time (Jagesh et al., 2013; Agrawal et al., 2014). However, in some cases, some morphological, biochemical and genetic changes could occur during plant regeneration (Nehra et al., 1992; Peredo et al., 2006; El-Dougdoug et al., 2007).

DNA markers are very useful to reveal genetic diversity between related genotypes because results are independent of plant age, type of tissue and environmental conditions. Different types of molecular markers such as RAPD, ISSR and SSR have been used widely for the detection of genetic variation between and within Cymbopogon species (Sangwan et al., 2001; Kumar et al., 2009; Adhikari et al., 2015).

In the present study we aimed at elucidating preliminary genetic diversity within a wild population of Cymbopogon schoenanthus subsp. proximus and within plants regenerated in vitro through somatic embryogenesis, direct and indirect 
organogenesis. Genetic relationship among wild genotypes and regenerated plants through different in vitro culture systems was studied to identify the best systems that may produce genetic fidelity and genetic diversity, that can be used in future conservation of plant germplasm and for genetic transformation.

\section{Materials and Methods}

\section{Plantmaterial}

C. schoenanthus leaves and mature inflorescences were collected from plants growing at Aswan University Botanical Garden, Egypt during spring 2014. The original source of this population is a 15 years-old transplant collected from Egypt-Sudan border, which was left to naturally grow and reproduce, with some occasional supplemental watering. The population consisted of a total of 32 individual plants, of which 15 were mature with inflorescences at different stages of maturity, the others were vegetative. Number of inflorescences/mature individual ranged from 3-30 and the number of flowers/inflorescence ranged from 58-310, of which an average of $50 \%$ producing seeds.

Inflorescences were collected from all 15 mature individuals (pale yellow). Seeds for in vitro cultures were collected randomly from all inflorescences.

\section{Chemicals}

Tissue culture media were purchased from PhytoTechnology Laboratories (Shawnee Mission, KS, USA). DNA extraction kits and Taq polymerase for PCR were purchased from (Promega, Madison, WI, USA) and DNA ladder from (Fisher Scientific, USA).

\section{In vitro regeneration of plants}

\section{Seed sterilization}

Mature seeds were collected from inflorescences $24 \mathrm{~h}$ prior to seed culture. Seeds were collected in cheesecloth, washed for $15 \mathrm{~min}$. under running tap water, followed by rinsing for $5 \mathrm{~min}$. in double distilled water. Seeds were then surface-sterilized by immersing in 95\% ethanol for $1 \mathrm{~min}$. followed by $20 \%$ Clorox solution for $20 \mathrm{~min}$., with stirring. Under aseptic conditions, Clorox solution was drained and the seeds were rinsed 3 times in sterile double distilled $\mathrm{H}_{2} \mathrm{O}$ before using as explants for all three tissue culture systems tested in this investigation.

\section{Somatic embryogenesis}

Embryogenic callus was induced from mature seeds on Murashige and Skoog medium (1962) with B5 vitamins (Gamborg et al., 1968) (MSB5) supplemented with $1 \mathrm{mg} \mathrm{L}^{1}$ 2,4-Dichlorophenoxy acetic acid (2,4 -D, Sigma, Saint Louis, MO, USA) and $0.5 \mathrm{mg} \mathrm{L}^{-1}$ 6-Benzyl adenine (BA, Sigma). First subculture was carried out on the same medium composition and growth regulator concentrations after 6 weeks. Embryogenic callus were transferred to MSB5 medium with $0.25 \mathrm{mg} \mathrm{L}^{-1} 2$, 4-D and $0.125 \mathrm{mg} \mathrm{L}^{-1} \mathrm{BA}$, and embryos were germinated on medium with $0.2 \mathrm{mg} \mathrm{L}^{-1} \mathrm{BA}$ and without 2, 4-D. Plantlets were transferred to MSB5 hormone free medium for root development. Subcultures were carried out at four weeks intervals, sucrose concentrations were $3 \%$ in induction and subculture media and $2 \%$ in the rooting medium (El-Bakry and Abdelsalam, 2012).

\section{Direct organogenesis}

Seeds were cultured on solid MSB5 medium supplemented with $7 \mathrm{mg} \mathrm{L}^{-1} \mathrm{BA}$ and $0.05 \mathrm{mg} \mathrm{L}^{-1} 1$ Naphthaleneacetic acid (NAA, Sigma). After 4 weeks, multiple shoots were initiated directly from the seed explant without forming callus. Root induction of these shoots was achieved by the addition of liquid MS media supplemented with $0.2 \mathrm{mg} \mathrm{L}^{-1} \mathrm{BA}$ to the solid induction medium. Elongation of the adventitious roots was achieved by applying hormone free liquid MSB5 medium directly to the solid medium in the original vessel. Plantlets were harvested after 10 weeks from initial seed culture (Abdelsalam et al., 2017b).

\section{Indirect organogenesis}

Morphogenic calli (non-embryogenic) were induced on MSB5 medium supplemented with $4 \mathrm{mg} / \mathrm{L}$ (NAA) and $0.5 \mathrm{mg} \mathrm{L}^{-1} \mathrm{BA}$ using seeds as explants. Four weeks later, morphogenic calli were subcultured on the same media. Indirect regenerated shoots were formed after 2-3 weeks from first subculture. Shoots were dissected (to individual shoots) and transferred to MSB5 hormone free medium supplemented with $6 \%$ sucrose to induce adventitious root formation. Healthy plantlets with roots were harvested after 10 weeks from initial seed culture.

For all experiments, $\mathrm{pH}$ of the media was adjusted to 5.8 before autoclaving. Media were solidified by adding $2 \mathrm{~g} \mathrm{~L}^{-1}$ phytagel (Sigma). Replications were 5 plates or magenta containers per treatment, with 5 seeds/culture vessel. Cultures were incubated at $25{ }^{\circ} \mathrm{C}$ under cool white fluorescent light (3000 lux) for 16/8 h light/dark photoperiod.

\section{DNA profiling \\ Sample collection}

In vitro propagated shoots from somatic embryogenesis, direct and indirect organogenesis methods were harvested on ice then lyophilized for $48 \mathrm{~h}$.

\section{DNA Extraction}

DNA was extracted according to Khanuja et al. (1999). DNA pellet was resuspended in $200 \mu$ of TE buffer (Tris EDTA buffer-10 mM Tris HCl, 1 mM EDTA, pH 8.0). DNA quality and concentration were determined using NanoDrop- $1000^{\circ} \quad$ Spectrophotometer (Nano-Drop Technologies, Wilmington, DE, USA). DNA was diluted to $100 \mathrm{ng} \mathrm{\mu l}^{-1}$ before use in PCR reactions.

\section{$P C R$ reactions, $R A P D, I S S R$ and $c p S S R$}

Each PCR reaction of $25 \mu \mathrm{l}$ was prepared as follows: one $\mu \mathrm{l}$ of $100 \mathrm{ng}^{-1} \mathrm{l}^{-1}$ template DNA, mixed with $5 \mu \mathrm{l} 5 \mathrm{X}$ Taq buffer, $2.5 \mu \mathrm{l}$ from $2 \mathrm{mM}$ dNTPs, $1 \mathrm{U}$ of Taq polymerase $(0.2 \mu \mathrm{l}), 2 \mu \mathrm{l}$ of $25 \mathrm{mM} \mathrm{MgCl} 2$ and $11.3 \mu \mathrm{l}$ of PCR-quality distilled water. A total of 18 DNA samples were used in ISSR and RAPD investigation. Those comprised of 3 genotypes from wild plants, five replications from each in vitro regeneration method. In cpSSR study, 22 genotypes 
224

were used: 4 genotypes from each of wild plants, and 6 plants from each regeneration system. Preliminary screen of DNA markers was carried out using 50 RAPD primers, 44 ISSR primers and $49 \mathrm{cpSSR}$ primers (Eurofins MWG Operon, AL, USA). Nucleotide sequences information of all ISSR and cPSSR primers is included in the supplementary data (Tables 7 and 8). Thermal cycling conditions were as follows: initial denaturation at $94^{\circ} \mathrm{C}$ for $4 \mathrm{~min}$. followed by 40 cycles of $1 \mathrm{~min}$ denaturation at $94^{\circ} \mathrm{C}$, $30 \mathrm{~s}$ annealing at the specified temperature for each primer, and $1 \mathrm{~min}$ extension at $72{ }^{\circ} \mathrm{C}$ and final extension for $10 \mathrm{~min}$ at $72^{\circ} \mathrm{C}$.

\section{Gel electrophoresis and DNA bands visualization}

PCR products were analyzed using $1.5 \%$ agarose gel and stained using ethidium bromide (Sigma). Resulting bands were visualized and photographed by Gel Doc XR+ imager (Bio-Rad, Hercules, California, USA). Bands sizes were determined by the aid of $1 \mathrm{~kb}$ plus DNA ladder (Fisher Scientific, USA).

\section{Data analysis}

Data were collected from at least three genotypes of wild plants and 5-6 genotypes for in vitro propagated plants of each tissue culture systems. Gel images were analyzed using Quantity One Software (BioRad Laboratories, Hercules, California). Reproducible bands were scored and entered into a binary data matrix sheet ( 1 for presence and 0 for absence). This analysis was carried out separately for each type of markers. To analyze the combined data from different markers, the binary data from ISSR, RAPD and cPSSR were combined into one excel sheet and analyzed. The binary data matrix was used to calculate Jaccard's similarity coefficient (Jaccard, 1908) using community analysis package software (CAP) by Henderson and Seaby (1999). The dendrograms were generated using unweighted pair group method with arithmetic average (UPGMA) clustering analysis based on Jaccard's similarity coefficient. The statistical analysis of the phylogenetic tree was confirmed by using 100-bootstrap replicates.

\section{Results and Discussion}

The regeneration systems used in the study are illustrated /summarized in Fig. 1. All systems produce healthy plants, but both types of organogenic systems produce plants in a shorter time span (2-3 months), than somatic embryogenesis (5-6 months).

The results for genetic polymorphism using different primer types are given below for ISSR, RAPDs, cPSSR and a combined analysis for all data regenerated irrespective of the primer type used.

\section{ISSR analysis}

Genetic diversity among different in vitro regeneration systems were analyzed using ISSR markers. Initially, fortyfour ISSR primers were tested with two samples per source, and 19 primers were selected depending on bands reproducibility and total amplified fragment. A total number of amplified fragments of 222 were generated with 24 monomorphic bands and 198 polymorphic bands.
Maximum number of amplified fragments was 16 with UBC842T, UBC857C and Y (TG) 7 primers. Minimum number of amplified bands was 8 with UBC846G primer (Table 1 in supplementary data). Some bands were unique to each regeneration system (Table 4). $\mathrm{R}(\mathrm{CA}) 7$ primer produced higher number of unique bands (16) (Fig. 3A), of which six bands in wild type, 4 bands within plants from somatic embryogenesis, 3 from each organogenesis systems. Polymorphism percentage among wild plant genotypes was $53.3 \%$, among SE plants was $57.9 \%$, among indirect regenerated plants was $48.1 \%$ and among direct regenerated plants was $46.7 \%$ (Table 1).

Dendrogram generated using UPGMA showed two main clusters. The first cluster included only plants regenerated through indirect organogenesis (Fig. 2A). The second cluster was divided into two sub-clusters: wild plant population in a separate sub-cluster, while in vitro regenerated plants through somatic embryogenesis and direct organogenesis in the other sub-cluster.

Jaccard's similarity index (Table 4 supplementary data) showed that, the highest genetic similarity value among groups was 0.51 between embryogenic plants and direct regenerated plants, while the lowest similarity value (0.28) was recorded between embryogenic plants and indirect regenerated plants. Similarity within direct regenerated plants population was higher $(0.62-0.86)$ compared to other in vitro regenerated systems. Among different in vitro propagated systems, plants regenerated through somatic embryogenesis showed higher similarity ranging $0.32-0.5$ to wild plant, while indirect regenerated plants were less similar to wild genotypes compared to other systems recording similarity between 0.32 and 0.36 .

\section{RAPD analysis}

Fifty RAPD primers were tested to study preliminary genetic diversity within the wild genotypes and in vitro regenerated plants, of which 14 primers were selected. A total of 139 fragments were produced by all primers, of which 24 were monomorphic and 115 were polymorphic bands. Primers OPB-03 and OPD-03 generated maximum number of amplified fragments (16), while lower number of amplified bands was 5 with OPK-07 and OPM-07 primers (Table 2 supplementary data). Some bands were unique to either regeneration system or to wild plant. Higher number of unique bands (6) was observed in indirect regenerated plants. Direct regenerated plants did not show any unique bands (Table 4). Wild genotypes showed 2 unique bands with base pair ranging from 711-700 and 1333-1294 in OPR-07 and 7N3D, respectively (Table 4). RAPD profiles of OPAC-07, OPZ07, OPD07, OPD03 primers are shown in (Fig. 3. E-H).

Polymorphism percentage within population of each plant source based on RAPD analysis was summarized in Table 2. Indirect regenerated plant population produced higher polymorphism percentage 43.5. Polymorphism percentage in direct regenerated plant population was low and close to that of wild plant population 35.3 and 34.1, respectively.

Dendrogram generated using UPGMA analysis separated the studied plants into 2 major clusters. 
Table 1. ISSR analysis within W=Wild, $S E=$ Somatic embryogenesis, $D=$ Direct regeneration and ID = Indirect regeneration genotypes. $T A F=T$ Total amplified fragments, $\mathrm{Mb}=$ Monomorphic bands, $\mathrm{Pb}=$ Polymorphic bands

\begin{tabular}{|c|c|c|c|c|c|c|c|c|c|c|c|c|c|}
\hline & \multirow{2}{*}{ Primer } & \multicolumn{3}{|c|}{ Wild } & \multicolumn{3}{|c|}{ SE } & \multicolumn{3}{|c|}{$\mathrm{D}$} & \multicolumn{3}{|c|}{ ID } \\
\hline & & TAF & Mb & $\mathbf{P b}$ & TAF & Mb & $\mathbf{P b}$ & TAF & Mb & $\mathbf{P b}$ & TAF & Mb & $\mathbf{P b}$ \\
\hline 1 & UBC810 & 8 & 3 & 5 & 8 & 4 & 4 & 5 & 5 & 0 & 4 & 4 & 0 \\
\hline 2 & UBC811 & 9 & 0 & 9 & 10 & 1 & 9 & 8 & 5 & 3 & 9 & 0 & 9 \\
\hline 3 & UBC819 & 5 & 2 & 3 & 3 & 2 & 1 & 4 & 4 & 0 & 7 & 7 & 0 \\
\hline 4 & UBC842C & 7 & 2 & 5 & 10 & 4 & 6 & 11 & 1 & 10 & 8 & 3 & 5 \\
\hline 5 & UBC842T & 6 & 3 & 3 & 14 & 1 & 13 & 13 & 3 & 10 & 5 & 3 & 2 \\
\hline 6 & UBC846A & 6 & 2 & 4 & 7 & 0 & 7 & 5 & 2 & 3 & 5 & 3 & 2 \\
\hline 7 & UBC846G & 4 & 4 & 0 & 7 & 2 & 5 & 5 & 3 & 2 & 7 & 3 & 4 \\
\hline 8 & UBC849C & 8 & 5 & 3 & 8 & 3 & 5 & 9 & 6 & 3 & 6 & 2 & 4 \\
\hline 9 & UBC849T & 6 & 3 & 3 & 8 & 1 & 7 & 9 & 4 & 5 & 7 & 6 & 1 \\
\hline 10 & UBC856C & 9 & 4 & 5 & 10 & 5 & 5 & 10 & 6 & 4 & 10 & 3 & 7 \\
\hline 11 & UBC856T & 10 & 5 & 5 & 8 & 7 & 1 & 8 & 6 & 2 & 5 & 5 & 0 \\
\hline 12 & UBC857C & 7 & 2 & 5 & 8 & 6 & 2 & 7 & 3 & 4 & 11 & 2 & 9 \\
\hline 13 & UBC857T & 10 & 4 & 6 & 11 & 5 & 6 & 10 & 9 & 1 & 10 & 8 & 2 \\
\hline 14 & UBC873 & 8 & 5 & 3 & 11 & 4 & 7 & 7 & 4 & 3 & 6 & 6 & 0 \\
\hline 15 & $\mathrm{R}(\mathrm{CA}) 7$ & 6 & 6 & 0 & 4 & 4 & 0 & 4 & 3 & 1 & 5 & 3 & 2 \\
\hline 16 & $\mathrm{Y}(\mathrm{TG}) 7$ & 11 & 5 & 6 & 9 & 8 & 1 & 12 & 3 & 9 & 6 & 3 & 3 \\
\hline 17 & UBC834T & 5 & 4 & 1 & 10 & 6 & 4 & 9 & 5 & 4 & 9 & 4 & 5 \\
\hline 18 & UBC860A & 2 & 1 & 1 & 9 & 1 & 8 & 6 & 5 & 1 & 8 & 2 & 6 \\
\hline \multirow[t]{3}{*}{19} & $\mathrm{CCC}(\mathrm{GT}) 6$ & 8 & 3 & 5 & 9 & 5 & 4 & 8 & 3 & 5 & 7 & 3 & 4 \\
\hline & Total & 135 & 63 & 72 & 164 & 69 & 95 & 150 & 80 & 70 & 135 & 70 & 65 \\
\hline & $\%$ & & 46.7 & 53.3 & & 42.1 & 57.9 & & 53.3 & 46.7 & & 51.9 & 48.1 \\
\hline
\end{tabular}

Table 2. RAPD analysis within $\mathrm{W}=\mathrm{W}$ ild, $\mathrm{SE}=$ Somatic embryogenesis, $\mathrm{D}=\mathrm{Direct}$ regeneration and $\mathrm{ID}=$ Indirect regeneration genotypes. $T$ AF= Total amplified fragments, $\mathrm{Mb}=$ Monomorphic bands, $\mathrm{Pb}=$ Polymorphic bands

\begin{tabular}{|c|c|c|c|c|c|c|c|c|c|c|c|c|c|}
\hline & \multirow{2}{*}{ Primer } & \multicolumn{3}{|c|}{ Wild } & \multicolumn{3}{|c|}{ SE } & \multicolumn{3}{|c|}{$\mathrm{D}$} & \multicolumn{3}{|c|}{ ID } \\
\hline & & TAF & Mb & $\mathbf{P b}$ & TAF & Mb & $\mathbf{P b}$ & TAF & Mb & $\mathbf{P b}$ & TAF & Mb & $\mathbf{P b}$ \\
\hline 1 & OPB-03 & 8 & 5 & 3 & 8 & 5 & 3 & 9 & 4 & 5 & 8 & 4 & 4 \\
\hline 2 & OPD-03 & 11 & 10 & 1 & 13 & 8 & 5 & 10 & 8 & 2 & 12 & 7 & 5 \\
\hline 3 & OPD-07 & 7 & 2 & 5 & 11 & 3 & 8 & 9 & 4 & 5 & 11 & 4 & 7 \\
\hline 4 & OPC-07 & 3 & 3 & 0 & 4 & 1 & 3 & 5 & 2 & 3 & 5 & 2 & 3 \\
\hline 5 & OPE-07 & 8 & 4 & 4 & 5 & 2 & 3 & 5 & 4 & 1 & 5 & 5 & 0 \\
\hline 6 & OPI-07 & 4 & 3 & 1 & 8 & 5 & 3 & 7 & 1 & 6 & 9 & 2 & 7 \\
\hline 7 & OPK-07 & 3 & 2 & 1 & 4 & 4 & 0 & 3 & 3 & 0 & 4 & 3 & 1 \\
\hline 8 & OPM-07 & 3 & 3 & 0 & 3 & 3 & 0 & 3 & 3 & 0 & 5 & 2 & 3 \\
\hline 9 & OPN-07 & 3 & 2 & 1 & 8 & 5 & 3 & 2 & 2 & 0 & 3 & 3 & 0 \\
\hline 10 & OPQ-07 & 7 & 5 & 2 & 7 & 5 & 2 & 8 & 6 & 2 & 8 & 4 & 4 \\
\hline 11 & OPR-07 & 5 & 3 & 2 & 5 & 4 & 1 & 4 & 4 & 0 & 5 & 3 & 2 \\
\hline 12 & OPV-07 & 9 & 2 & 7 & 4 & 4 & 0 & 6 & 4 & 2 & 5 & 5 & 0 \\
\hline 13 & OPZ-07 & 6 & 5 & 1 & 7 & 4 & 3 & 8 & 6 & 2 & 8 & 6 & 2 \\
\hline 14 & OPAC-07 & 5 & 5 & 0 & 4 & 3 & 1 & 6 & 4 & 2 & 4 & 2 & 2 \\
\hline \multicolumn{2}{|r|}{ Total } & 82 & 54 & 28 & 91 & 56 & 35 & 85 & 55 & 30 & 92 & 52 & 40 \\
\hline \multicolumn{2}{|r|}{$\%$} & & 65.9 & 34.1 & & 61.5 & 38.5 & & 64.70 & 35.30 & & 56.5 & 43.5 \\
\hline
\end{tabular}

Table 3. cpSSR analysis within wild plants and in vitro regenerated plant groups (W=Wild, $S E=$ somatic embryogenesis, $D=$ direct, $I D=I n d i r e c t$ organogenesis).TAF= Total amplified fragments, $\mathrm{Mb}=$ Monomorphic bands, $\mathrm{Pb}=$ Polymorphic bands

\begin{tabular}{|c|c|c|c|c|c|c|c|c|c|c|c|c|c|}
\hline & \multirow{2}{*}{ Primer } & \multicolumn{3}{|c|}{ Wild } & \multicolumn{3}{|c|}{ SE } & \multicolumn{3}{|c|}{$\mathrm{D}$} & \multicolumn{3}{|c|}{ ID } \\
\hline & & TAF & Mb & $\mathbf{P b}$ & TAF & Mb & $\mathbf{P b}$ & TAF & Mb & $\mathbf{P b}$ & TA & Mb & $\mathbf{P b}$ \\
\hline 1 & $\begin{array}{l}\text { VgcpSSR5-F } \\
\text { VgcpSSR5-R }\end{array}$ & 1 & 1 & 0 & 1 & 1 & 0 & 1 & 0 & 1 & 1 & 1 & 0 \\
\hline 2 & $\begin{array}{l}\text { CCMP1-F } \\
\text { CCMP1-R }\end{array}$ & 6 & 3 & 3 & 4 & 1 & 3 & 4 & 2 & 2 & 5 & 1 & 4 \\
\hline 3 & $\begin{array}{l}\text { CCMP2-F } \\
\text { CCMP2-R }\end{array}$ & 7 & 1 & 6 & 6 & 4 & 2 & 7 & 2 & 5 & 8 & 4 & 4 \\
\hline 4 & $\begin{array}{l}\text { trnK intron-F } \\
\text { trnK intron- } \mathrm{R}\end{array}$ & 2 & 2 & 0 & 2 & 1 & 1 & 2 & 2 & 0 & 1 & 1 & 0 \\
\hline 5 & $\begin{array}{l}\text { psbK-psbI-F } \\
\text { psbK-psbI-R }\end{array}$ & 1 & 1 & 0 & 1 & 1 & 0 & 1 & 1 & 0 & 1 & 1 & 0 \\
\hline 6 & $\begin{array}{l}\text { rpoC2-rps2-F } \\
\text { rpoC2-rps2-R }\end{array}$ & 1 & 1 & 0 & 1 & 1 & 0 & 1 & 1 & 0 & 0 & 0 & 0 \\
\hline 7 & $\begin{array}{l}\text { atpI-atpH-F } \\
\text { atpI-atpH-R }\end{array}$ & 0 & 0 & 0 & 1 & 1 & 0 & 0 & 0 & 0 & 0 & 0 & 0 \\
\hline & Total & 18 & 9 & 9 & 16 & 10 & 6 & 16 & 8 & 8 & 16 & 8 & 8 \\
\hline & $\%$ & & 50 & 50 & & 62.5 & 37.5 & & 50 & 50 & & 50 & 50 \\
\hline
\end{tabular}


Table 4. Unique bands in wild plants and in vitro regenerated plant groups (W= wild, $\mathrm{SE}=$ somatic embryogenesis, $\mathrm{D}=\mathrm{direct}, \mathrm{ID}=$ indirect organogenesis)

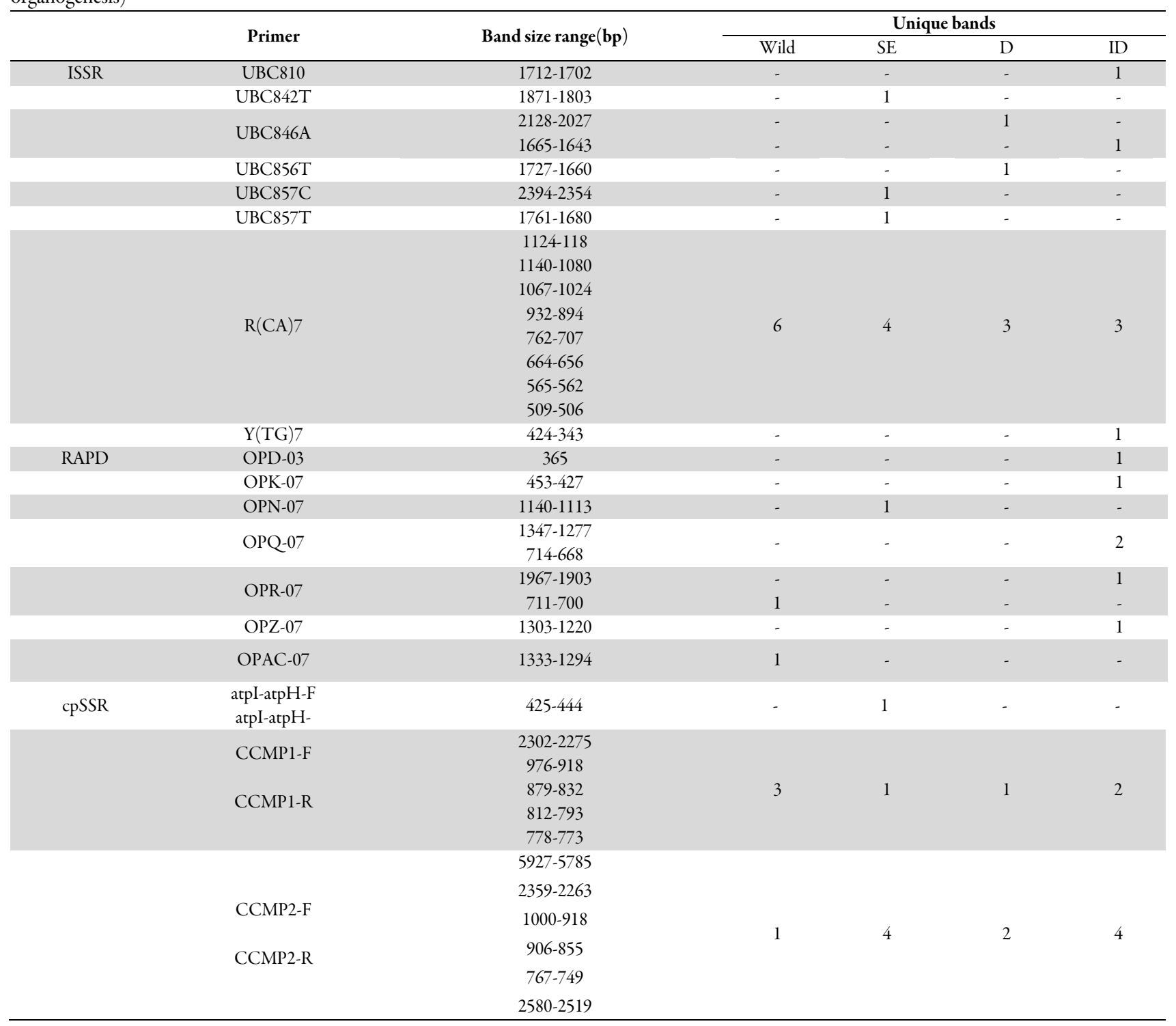

Table 5. Polymorphism percentage within studied plants groups ( $\mathrm{W}=$ wild, $\mathrm{SE}=$ somatic embryogenesis, $\mathrm{D}=$ direct, $\mathrm{ID}=$ indirect organogenesis)

\begin{tabular}{ccccc}
\hline $\begin{array}{c}\text { Protocol } \\
\text { Genotypes }\end{array}$ & ISSR & RAPD & cPSSR & All markers \\
\hline W & 53.3 & 34.1 & 50 & 45.8 \\
SE & 57.9 & 38.5 & 37.5 & 44.6 \\
D & 46.7 & 35.3 & 50 & 44.0 \\
ID & 48.1 & 43.5 & 50 & 47.2 \\
All genotypes & 51.5 & 37.85 & 46.87 & \\
\hline
\end{tabular}

The first cluster included wild genotypes and somatic embryogenic plants, while second cluster included in vitro regenerated plants from direct and indirect organogenesis (Fig. 2B).

Jaccard's similarity index is presented in Table 5, supplementary data. Wild plants and embryogenic plants showed higher similarity value among the studied groups (0.64), while indirect regenerated and wild plants showed less similarity (0.46). Similarity values within groups showed that, direct regenerated plants population produced higher within similarity (0.94). 


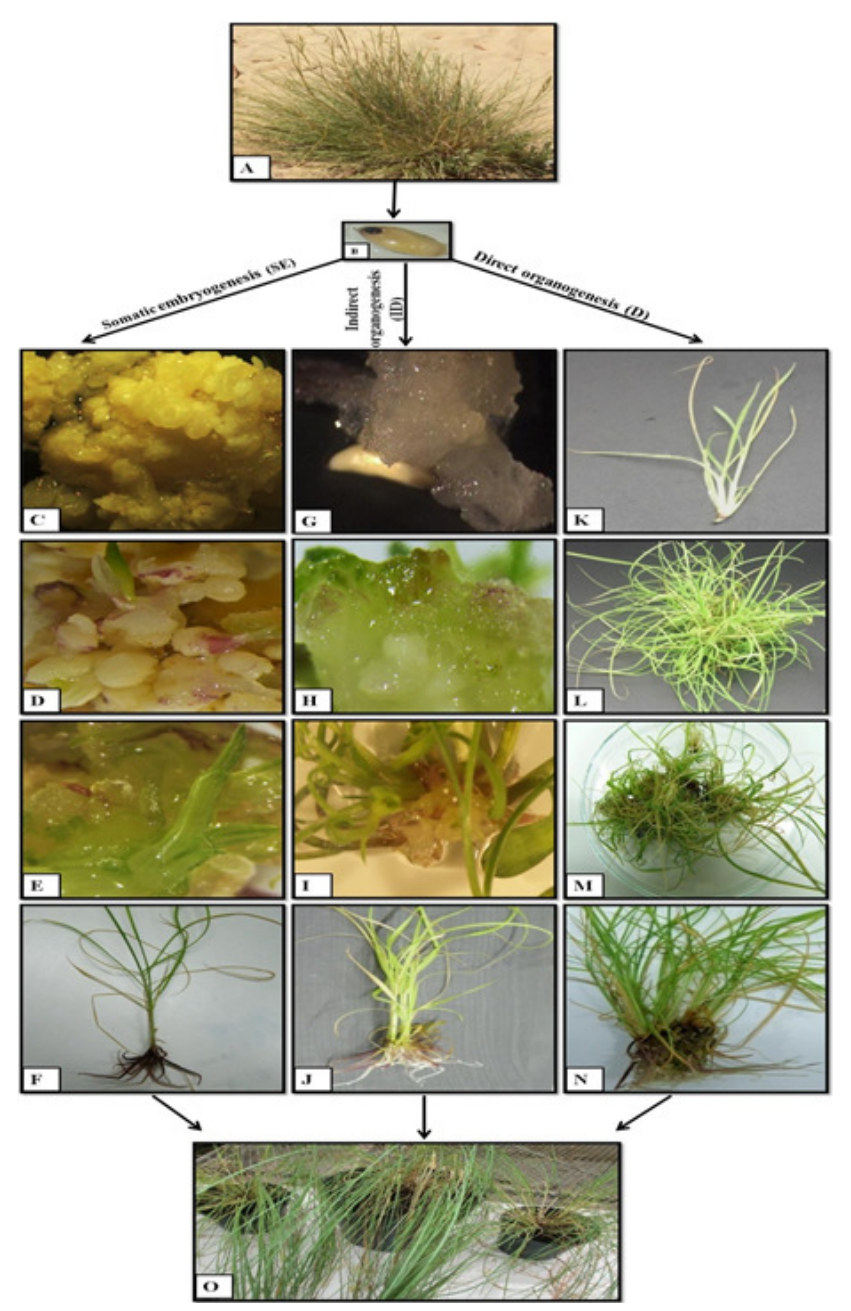

Fig. 1. In vitro regeneration from C. schoenanthus subsp. proximus:(A) Wild plant with mature inflorescence; (B) Mature seed under light microscope; (C) Embryogenic callus, (D) Embryogenic callus with mature somatic embryos; (E) Embryogenic callus with germinating somatic embryos; (F) Rooted plant; $(\mathrm{G})$ Non embryogenic callus; $(\mathrm{H})$ Organogenic callus; (I) Indirect regenerated shoots; (J) Rooted plant; (K) Direct regenerated shoots 1 week old; (L) Direct regenerated shoots 3 weeks old; (M) Direct regenerated shoots 5 weeks old; (N) Rooted plant and $(\mathrm{O})$ Acclimatized plant

\section{cpSSR analysis}

Genetic similarities among and within in vitro regenerated plants through different tissue culture systems and wild plants were studied using cpSSR DNA markers. Out of 49 primers screened (Table 8 , supplementary data), 7 primers were selected. Total number of fragments was 29 that include 23 polymorphic bands and 6 monomorphic bands among all studied groups (Table 3, supplementary data). Each system of the in vitro regenerated plants was characterized by unique bands (Table 4). CCMP2 primer (Fig. 3I) produced higher number of unique bands (11 bands), of which 4 bands in each of the indirect organogenic plants and somatic embryogenic plants. Wild plants were characterized by one unique band.

Polymorphism percentage within wild, direct organogenic and indirect organogenic populations were $50 \%$. Somatic embryogenesis system showed less within population polymorphism percentage (37.5, Table 3 ).

Dendrogram generated using UPGMA analysis for cpSSR data separated plants regenerated through indirect organogenesis into one cluster, while the wild and in vitro regenerated plants through direct organogenesis and somatic embryogenesis into a second separate cluster (Fig. $2 \mathrm{C})$. Wild genotypes and somatic embryogenesis genotypes were grouped into 2 sub-clusters and separate from the direct regenerated genotypes. Jaccard's similarity coefficient calculated Table 6 (supplementary data), showed that among in vitro regenerated plants, somatic embryogenic regenerated plants were more similar to wild plants with similarity value $(0.35-0.67)$. Direct regenerated plants showed high within population similarity range $(0.5-0.92)$ within the population.

\section{Combined markers analysis}

Combined ISSR, RAPD and cpSSR markers produced a total of 386 bands with 334 polymorphic bands. Jaccard's similarity coefficient among studied groups showed that, plants produced from somatic embryogenesis were more similar to wild plants when compared to plants regenerated from organogenesis. Dendrogram generated using UPGMA data analysis showed same highest similarity of plants regenerated from somatic embryogenesis to the wild (Fig. 4).

The DNA profiles generated based on ISSR, RAPD and cPSSR marker systems were found to be uniform in elucidating genetic diversity of within and among wild plants and those regenerated through different in vitro culture systems. 

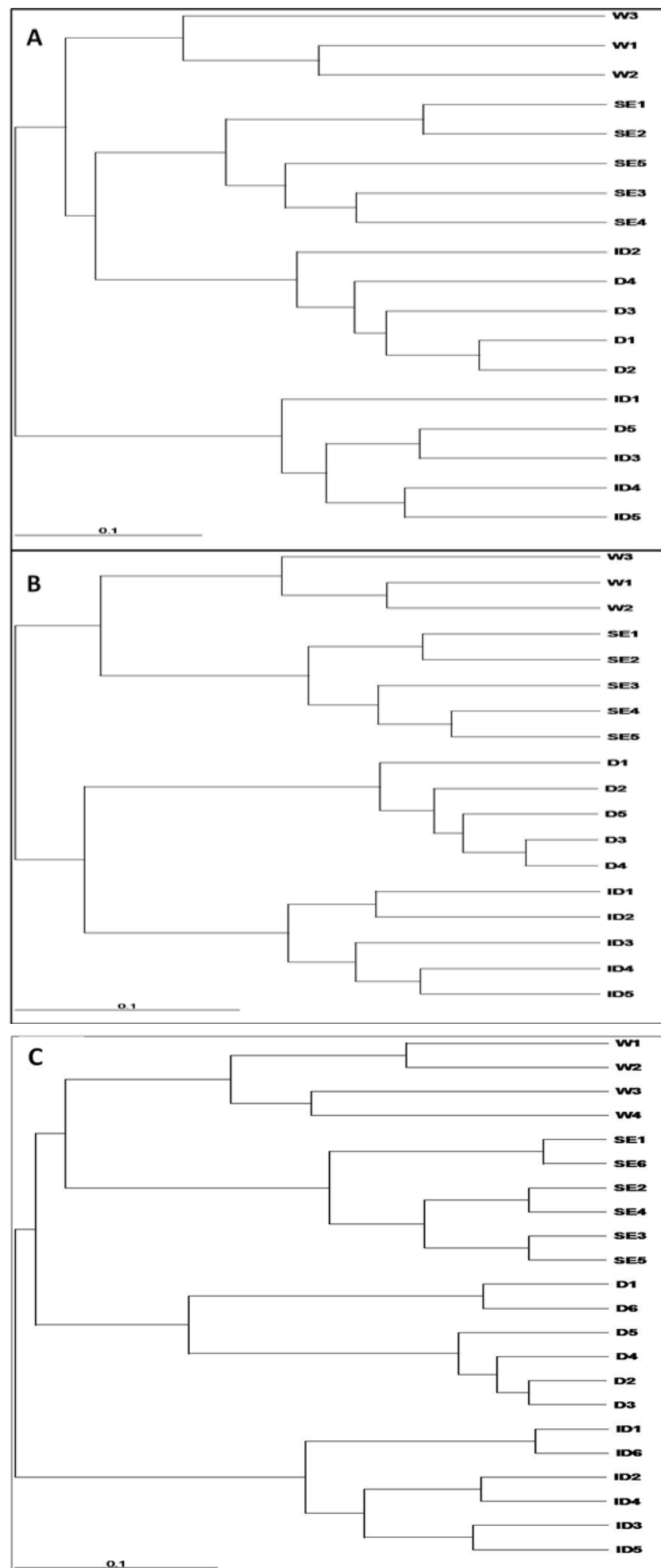

Fig. 2. Dendrogram generated using UPGMA analysis estimated by Jaccard similarity coefficient (100 bootstrap)based on different markers:(A) ISSR, (B) RAPD, (C) cpSSR, for wild plants (W) and in vitro regenerated plants from somatic embryogenesis (SE), direct organogenesis (D) and indirect organogenesis (ID)

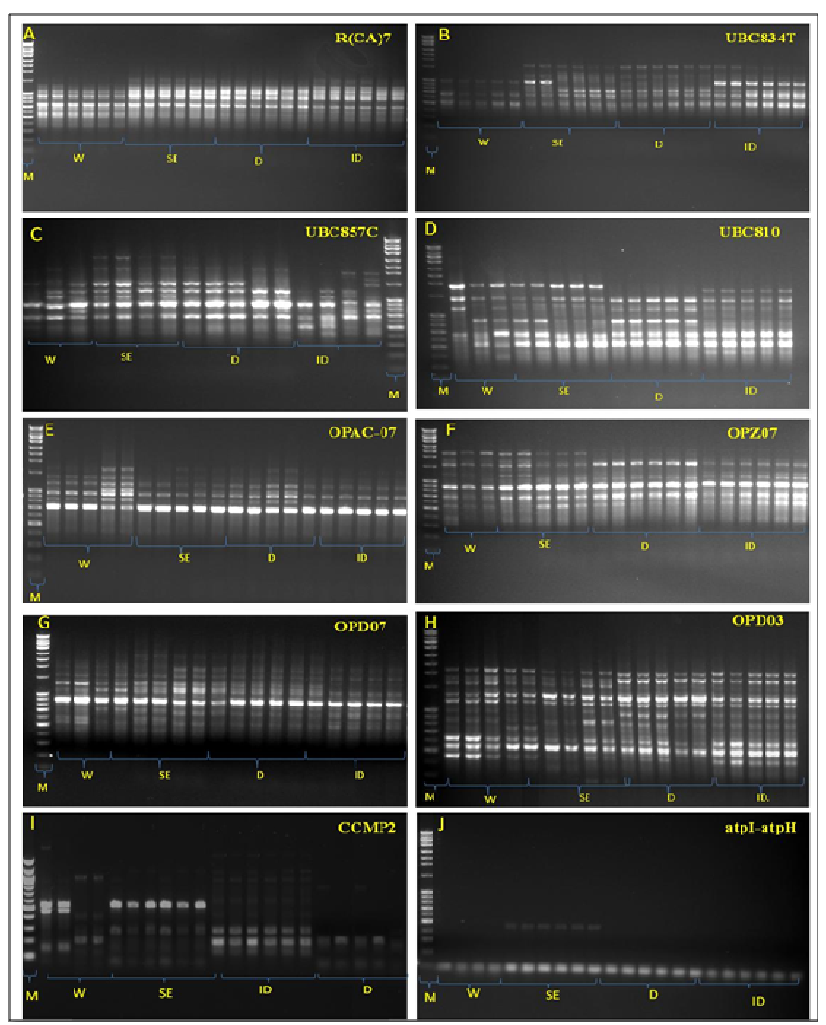

Fig. 3. Gel profiling of wild $=\mathrm{W}$, in vitro regenerated plants through somatic embryogenesis (SE), direct organogenesis(D), indirect organogenesis (ID) using ISSR analysis (A-D), RAPD (E-H),cpSSR I,J. M= DNA marker, 100-10000 bp

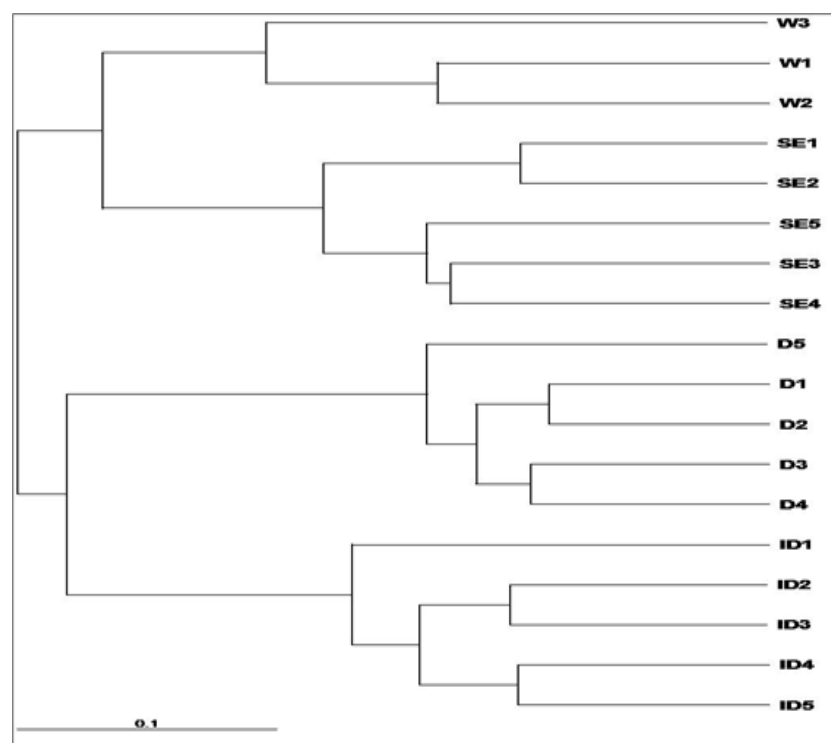

Fig. 4. UPGMA dendrogram generated using Jaccard similarity coefficient and 100 bootstrap for the genetic fidelity of in vitro regenerated shoots: $\mathrm{SE}=$ somatic embryogenesis, $\mathrm{D}=$ direct organogenesis, $\mathrm{ID}=$ indirect organogenesis) in comparison to $\mathrm{W}=$ wild plants, based on the combined data analysis of ISSR, RAPD and cPSSR primers 
Table 6. Jaccard's similarity coefficient range within studied plant groups $(\mathrm{W}=$ wild, $\mathrm{SE}=$ somatic embryogenesis, $\mathrm{D}=\mathrm{direct}, \mathrm{ID}=$ indirect organogenesis)

\begin{tabular}{cccccccc}
\hline Protocol/Genotypes & \multicolumn{2}{c}{ ISSR } & \multicolumn{2}{c}{ RAPD } & \multicolumn{2}{c}{ cPSSR } \\
\hline W & Range & Average & Range & Average & Range & Average \\
SE & $0.52-0.69$ & 0.59 & $0.70-0.80$ & 0.74 & $0.55-0.80$ & 0.67 \\
D & $0.52-0.8$ & 0.64 & $0.69-0.87$ & 0.78 & $0.65-0.94$ & 0.79 \\
ID & $0.62-0.86$ & 0.72 & $0.79-0.94$ & 0.85 & $0.61-0.93$ & 0.75 \\
\hline
\end{tabular}

Table 7. Jaccard's similarity coefficient range between wild plants $(\mathrm{W})$ and in vitro regenerated plants $\mathrm{SE}=$ somatic embryogenesis, $\mathrm{D}=$ direct, $\mathrm{ID}=$ indirect organogenesis)

\begin{tabular}{ccccccc}
\hline & \multicolumn{2}{c}{ ISSR } & & RAPD & & \\
& Range & Average & Range & Average & 0.55 & $0.35-0.67$ \\
W vs SE & $0.36-0.5$ & 0.45 & $0.49-0.64$ & $0.41-0.46$ & 0.43 & $0.38-0.53$ \\
W vs D & $0.35-0.44$ & 0.39 & $0.42-0.55$ & 0.5 & 0.43 \\
W vs ID & $0.32-0.36$ & 0.34 & 0.45 & 0.36 \\
\hline
\end{tabular}

Table 8. Jaccard's similarity coefficient based on combined data analysis ofISSR, RAPD, cpSSR for wild plants (W), in vitro regenerated plants through somatic embryogenesis(SE), direct organogenesis(D) and indirect organogenesis (ID)

\begin{tabular}{|c|c|c|c|c|c|c|c|c|c|c|c|c|c|c|c|c|c|c|}
\hline 0 & W 1 & W 2 & W 3 & SE 1 & SE 2 & SE 3 & SE 4 & SE 5 & D 1 & D2 & D 3 & D 4 & D5 & ID 1 & ID 2 & ID 3 & ID 4 & ID 5 \\
\hline W1 & 1 & & & & & & & & & & & & & & & & & \\
\hline W2 & 0.75 & 1 & & & & & & & & & & & & & & & & \\
\hline W3 & 0.60 & 0.63 & 1 & & & & & & & & & & & & & & & \\
\hline SE 1 & 0.49 & 0.53 & 0.52 & 1 & & & & & & & & & & & & & & \\
\hline SE 2 & 0.51 & 0.52 & 0.49 & 0.81 & 1 & & & & & & & & & & & & & \\
\hline SE 3 & 0.49 & 0.50 & 0.45 & 0.68 & 0.71 & 1 & & & & & & & & & & & & \\
\hline SE 4 & 0.49 & 0.49 & 0.43 & 0.64 & 0.68 & 0.75 & 1 & & & & & & & & & & & \\
\hline SE 5 & 0.47 & 0.49 & 0.43 & 0.59 & 0.63 & 0.74 & 0.73 & 1 & & & & & & & & & & \\
\hline D1 & 0.41 & 0.42 & 0.39 & 0.42 & 0.43 & 0.46 & 0.46 & 0.46 & 1 & & & & & & & & & \\
\hline D2 & 0.41 & 0.43 & 0.40 & 0.41 & 0.42 & 0.44 & 0.46 & 0.44 & 0.82 & 1 & & & & & & & & \\
\hline D3 & 0.41 & 0.43 & 0.41 & 0.43 & 0.43 & 0.48 & 0.45 & 0.46 & 0.75 & 0.83 & 1 & & & & & & & \\
\hline D4 & 0.42 & 0.44 & 0.42 & 0.42 & 0.45 & 0.46 & 0.45 & 0.45 & 0.73 & 0.79 & 0.82 & 1 & & & & & & \\
\hline D5 & 0.41 & 0.42 & 0.39 & 0.40 & 0.41 & 0.43 & 0.45 & 0.43 & 0.67 & 0.74 & 0.75 & 0.78 & 1 & & & & & \\
\hline ID1 & 0.39 & 0.42 & 0.40 & 0.42 & 0.43 & 0.44 & 0.49 & 0.48 & 0.51 & 0.46 & 0.46 & 0.48 & 0.48 & 1 & & & & \\
\hline ID2 & 0.40 & 0.42 & 0.39 & 0.41 & 0.39 & 0.42 & 0.44 & 0.47 & 0.44 & 0.41 & 0.44 & 0.45 & 0.45 & 0.75 & 1 & & & \\
\hline ID3 & 0.40 & 0.40 & 0.41 & 0.40 & 0.37 & 0.41 & 0.43 & 0.45 & 0.45 & 0.42 & 0.44 & 0.47 & 0.47 & 0.68 & 0.79 & 1 & & \\
\hline ID4 & 0.40 & 0.40 & 0.42 & 0.40 & 0.38 & 0.40 & 0.43 & 0.43 & 0.48 & 0.45 & 0.46 & 0.48 & 0.48 & 0.65 & 0.70 & 0.77 & 1 & \\
\hline ID5 & 0.39 & 0.40 & 0.40 & 0.39 & 0.38 & 0.40 & 0.44 & 0.44 & 0.47 & 0.45 & 0.43 & 0.46 & 0.46 & 0.66 & 0.70 & 0.74 & 0.80 & 1 \\
\hline
\end{tabular}

\section{Discussion}

Although the studied wild population was limited in number and origin, but due to the high medicinal value of the species and its potential use in the future, the present work was carried out to explore the genetic diversity using different markers, that is expected to be the basis for future genetic analysis of genotypes from different geographical areas, where the species is known to grow. Also, because the information on the biotechnology in the genus Cymbopogon is quite rich (Kumar et al., 2009; Quiala et al., 2016; Baruah et al., 2017), but poor on C. schoenanthus, both the different in vitro culture regeneration systems (El-Bakry and Abdelsalam, 2012; Abdelsalam et al., 2015; Abdelsalam et al., 2017b), their genetic analysis and their correlation with the wild genotypes would lay the basis for future genetic improvement of the species for producing high-value genotypes using different avenues of plant biotechnology.

Micro propagation using different in vitro culture protocols is an efficient technology for the rapid and continuous supply of the important plants using a limited space under controlled nutrients and environmental conditions (Debnath et al., 2006). In some cases, genetic variation occurs in the in vitro regenerated plants (somaclonal variation) due to use of supra-optimum concentration of growth regulators and continuous subculturing (Nehra et al., 1992; Martins et al., 2006).

Epigenetic variation plays a role in trans-generational stress-adaption of plants (Weinhold, 2018). A number of epigenetic variations have been reported in family Gramineae including rice and wheat (Chen and Zhou, 2013; Venetsky et al., 2015; Lanciano and Mirouze, 2017). Some studies reported that, the in vitro regenerated plants showing genetic dissimilarity as a result of genetic and/or epigenetic variation (Smulders and Klerk, 2011; Machczyńska et al., 2015).

Molecular markers have been considered as a fast and reliable method for determining genetic fidelity and distinguishing related populations (Semagn et al., 2006; Thorat et al., 2017).

RAPD and ISSR molecular markers have been used to evaluate genetic diversity in the genus Cymbopogon (Sangwan et al., 2001; Khanuja et al., 2006; Kumar et al., 2009). 
230

In the present study preliminary genetic polymorphism within wild plant population genotypes using ISSR primer analysis was $53.3 \%$, using RAPD was $31.4 \%$ and in using cPSSR was $16.1 \%$. Adhikari et al. (2015) detected a wide range of genetic polymorphism $(81.81,36.36,5.19)$ in 3 species of the genus Cymbopogon (C. martinii, C. flexuosus and $C$. winterianus) based on ISSR analysis. Debajit et al. (2015) reported higher polymorphism percentage (82.7) in C. flexuosus.

Our data showed that, genetic polymorphism among in vitro regenerated plants using ISSR markers was higher when compared to RAPD primers. These data agree with Bishoyi et al. (2016), where they reported that ISSR primers produced higher polymorphism values in comparison with RAPD primers in nine varieties of genus Cymbopogon due to the abundant microsatellite diversity in the genome compared to random primer sequences. Metabolic profiling, as signified by NMR spectroscopy (Abdelsalam et al., 2017a), showed that shoots regenerated through somatic embryogenesis were the closest in their metabolic profile to the wild plant population than direct and indirect regenerated plants, in agreement with the present DNA polymorphism, where all analysis grouped the wild and somatic embryogenesis regenerated plants in the same cluster or sub-cluster.

In vitro regenerated plants are genetically similar to wild type and polymorphism exhibited is a mere reflection of variations present within the wild type populations. Bhattacharya et al. (2009) evaluated the genetic fidelity of in vitro propagated Cymbopogon martini plants from rhizome culture using ISSR primers; regenerated plants were genetically similar to donor plants. In vitro regeneration of genetically stable Simmondsia chinensis, Alpinia galangal, Musa spp. and Artemisia nilagirica plants has been carried out in different studies (Kumar et al., 2011; Parida et al., 2011; Agrawal et al. 2014; Shinde et al., 2016).Genetic polymorphism among wild plant population genotypes was close to genetic polymorphism in in vitro regenerated systems using ISSR, RAPD, cpSSR primers, but similarity coefficients were quite low indicating low levels of genetic fidelity between the wild and in vitro regenerated plants in our study.

Chloroplast microsatellite (cpSSR) markers have been considered a very useful tool to detect and analyse various forms of genetic diversity such as differentiation and spatial structure among and within populations (Walter and Epperson, 2004).cpSSR makers were used to analyse genetic diversity among and within a range of plant populations, Phumichai et al. (2015) studied the genetic diversity of eight populations of Hevea rubber genotypes collected from different countries. Genetic variation of two species in the sea grass genus Zostera has been examined by Provan $e t$ al. (2008). In this study, cpSSR analysis showed high polymorphism ratio within wild plant (50\%) and in vitro regenerated plant through direct and indirect regenerated plant (50\%). Cesare et al. (2010) reported that, cpSSR markers were highly polymorphic by analysing different genotypes from Miscanthus and related species belong to subfamily Panicoideae including Cymbopogon citratus. Our data showed that, UPGMA dendrogram generated using
cPSSR data separated the studied plants to two main clusters, wild, embryogenic and direct regenerated plants in one cluster and the indirect regenerated plants in the other. Salvi et al. (2001) and Gunathilake et al. (2008) described the plants regenerated from direct organogenesis as a safe method for avoiding somaclonal variation, while indirect organogenesis showed higher probability to somaclonal variation (Ramírez-Mosqueda and Iglesias-Andreu, 2015).

Our data showed that, cluster analysis based on ISSR, RAPD and cPSSR separately or using a combined data analysis, plants from somatic embryogenesis and organogenesis were separated into different clusters and wild plants were grouped with the plants regenerated through somatic embryogenesis.

\section{Conclusions}

The present work represents a preliminary study of genetic polymorphism in C. schoenanthus subsp. proximus, collected from Africa. The different DNA marker methods used showed moderately low polymorphism within both the wild genotypes and within the plants regenerated through the different in vitro culture systems. UPGAMA analyses and Jaccard's similarity data suggested that plants regenerated through somatic embryogenesis and the wild plants are more similar compared to the plants regenerated through the organogenic systems, indicating that somatic embryogenesis system may be a better choice for future studies towards achieving higher level of clonal fidelity and genetic transformation of the species. The high similarity coefficient manifested within genotypes of plants regenerated through direct organogenesis, and its relatively close similarity to the wild genotypes, suggests its future use for ex-situ conservation. The relatively higher genetic polymorphism within plants regenerated through indirect de novo organogenesis, suggests their future use in generating and studying genetic variation for the production of high value genotypes of this medicinal plants species. Also, further genetic analysis of other populations of the species in Africa would be both necessary and valuable for the evaluation of the species gene pool, its conservation status and future economic use.

\section{Acknowledgements}

This research work was financially supported by the Culture Affairs and Missions Sector, Ministry of Higher Education, Egypt.

\section{Conflicts of interest}

The authors declare that there are no conflicts of interest related to this article.

\section{References}

Abdelsalam AM, ChowdhuryK, El-Bakry AA (2015). Effect of sugar types, culture age, concentrations of 2, 4D and sucrose on somatic embryogenesis of Cymbopogon schoenanthus subsp. proximus. Plant Tissue Culture \& Biotechnology 25(1):51-62. 
Abdelsalam A, Mahran E, Chowdhury K, Boroujerdi A, El-Bakry A (2017a). NMR-based metabolomic analysis of wild, greenhouse, and in vitro regenerated shoots of Cymbopogon schoenanthus. subsp. proximus with GC-MS assessment of proximadiol. Physiology and Molecular Biology of Plants 23(2):369-383.

Abdelsalam A, Chowdhury K, El-Bakry A (2017b). Micropropagation through in vitro tillering from seed cultures of the medicinal plant Cymbopogon schoenanthus subsp. proximus. Asian Journal of Applied Science 5(1):31-40.

AdhikariS, SahaS, Bandyopadhyay TC, Ghosh P(2015). Efficiency of ISSR marker for characterization of Cymbopogon germplasms and their suitability in molecular barcoding. Plant Systematic and Evolution 301(1):439 450 .

Agrawal A, Sanayaima R, Singh R, Tandon R, Verma S, Tyagi RK (2014). Phenotypic and molecular studies for genetic stability assessment of cryopreserved banana meristem derived from field and in vitro explant sources. In Vitro Cellular and \& Developmental Biology-Plant 50(3):345-356.

Baruah J, Gogoi B, Das K, Ahmed NM, Sarmah DK, La M, Bhau BS (2017). Genetic diversity study amongst Cymbopogon species from NEIndia using RAPD and ISSR markers. Industrial Crops and Products 95:235-243.

Bhattacharya S, Bandopadhtay TK, Ghosh PD (2009).Somatic embryogenesis in Cymbopogon pendulus and evaluation of clonal fidelity of regenerates using ISSR marker. Scientia Horticulturae 123(4):505513.

Bishoyi AK, Sharma A, Kavane A, Geetha KA (2016). Varietal discrimination and genetic variability analysis of Cymbopogon using RAPD and ISSR markers analysis. Applied Biochemistry and Biotechnology 179(4):659-670.

Boulos L (1983). Medicinal plants of North Africa. Reference Publication Inc. Michigan, USA.

BoulosL (1999).Flora of Egypt. Al Hadara publishing, Cairo, Egypt.

Cesare M, Hodkinson TR, Barth S (2010). Chloroplast DNA markers (cpSSRs, SNPs) for Miscanthus, Saccharum and related grasses (Panicoideae, Poaceae). Molecular Breeding26(3):539-544.

Chen X, Zhou DX (2013). Rice epigenomics and epigenetics: challenges andopportunities. Current Opinion in Plant Biology 16(2):164169.

DebajitS, SukritiD, Sneha G, Mohan L, Singh BB (2015).RAPD and ISSR based Intra-specific molecular genetic diversity analysis of Cymbopogon flexwosus L. Stapf with a distinct correlation of morpho-chemical observations. Research Journal of Biotechnology 10(7):105-113.

Debnath M, Malik CP, Bisen PS (2006). Micropropagation: A tool for the production of high quality plant-based medicines. Current Pharmaceutical Biotechnology 7(1):33-49.

El Taher K, Abdel-Kader MS (2008). Chemical and pharmacological study of Cymbopogon proximus volatile oil. Research Journal of Medicinal Plants2(2):53-60.

El-Askary HI, Meselhy MR, Galal AM (2003). Sesquiterpenes from Cymbopogon proximus. Molecules 8(9):670-677.

El-Bakry AA, Abelsalam AM (2012). Regeneration from embryogenic callus and suspension cultures of the wild medicinal plant Cymbopogon schoenanthus. African Journal of Biotechnology 11(43):10098-10107.
El-Dougdoug KA, El Harthi HMS, Korkar HM, Taha RM (2007). Detection of somaclonal variations in banana tissue culture using isozyme and DNA fingerprinting analysis. Journal of Applied Sciences Research 3(7):622-627.

Gamborg OL, Miller RA, Ojima K (1968). Nutrient requirements of suspension culture of soybean root cells. Experimental Cell Research 50(1):151-158.

Gunathilake PMPC, Abayagunawardhana N, Wilamasiri S, Sangakkara UR, EeswaraJP (2008). Direct shoot organogenesis from nodal and leat explants of Munronia pinnata (Wall.) Theob: a valuable medicinal plant. Tropical Agriculture Research 20:213-225.

Jaccard P (1908). Nouvelles recherchés sur la distribution florale. Bulletin de la SocieteVaudoise des Sciences Naturelles 44:223-270.

Khanuja SPS, Shasany AK, Darokar MP, Kumar S (1999). Rapid isolation of DNA from dry and fresh samples of plants producing large amounts of secondary metabolites and essential oils. Plant Molecular Biology Reporter 17(1):1-7.

Khanuja SPS, Shasany AK, Pawar A, Lal RK, Darokar MP, Naqvi AA, ... Kumar S (2006). Essential oil constituents and RAPD markers to establish species relationships in Cymbopogon Spreng. (Poaceae). Biochemical Systematic \& Ecology 33(2):171-186.

Kumar J, Verma V, Goyal A, Shahi AK, Sparoo R, Sangwan RS, Qazi GN (2009). Genetic diversity analysis in Cymbopogon species using DNA markers. Plant Omics 2(1):20-29.

Kumar S, Mangal M, Dhawan AK, Singh N (2011). Assessment of genetic fidelity of micropropagated plants of Simmondsia chinensis (Link) Schneider using RAPD and ISSR markers. Acta Physiologiae Plantarum 33(6):2541-2545.

Lanciano S, Mirouze M (2017).DNA Methylation in rice and relevance for breeding. Epigenomes 1(2):1-13.

Locksley HD, Fayez MBE, Radwan AS, Chari VM, Cordell GA, Wagner H (1982). Constituents of local plants XXV, Constitution of the antispasmodic principle of Cymbopogon proximus. Planta Medica 45(2):20-22.

Machczyńska J, Orlowska R, Zimny J, Bednarek PT (2014). Extended metAFLP approach in studies of tissue culture induced variation (TCIV) in triticale. Molecular Breeding 34(3):845-854.

Martins SR, Vences FJ, Miera LES, Barroso MR, Carnide V (2006). RAPD analysis of genetic diversity among and within Portuguese landraces of common white bean (Phaseolus vulgaris L.). Scientia Horticulturae 108(2):133-142.

Murashige T, Skoog F (1962). A revised medium for rapid growth and bioassay with tobacco tissue culture. Plant Physiology 15(3):473-497.

Nehra NS, Kartha KK, Stushnoff C, Giles KL (1992). The influence of plant growth regulator concentrations and callus age on somaclonal variation in callus culture regenerates of strawberry. Plant Cell, Tissue \& Organ Culture 29(3):257-268.

Peredo EL, Revilla MA, Arroyo-Garci'a R (2006). Assessment of genetic and epigenetic variation in hop plants regenerated from sequential subcultures of organogenic calli. Journal of Plant Physiology 163(10):1071-1079.

Phumichai C, Phumichai T, Wongkaew A (2015). Novel chloroplast microsatellite (cpSSR) markers for genetic diversity assessment of cultivated and wild Hevea Rubber. Plant Molecular Biology Reporter 
232

33(5):1486-1498.

Quiala E, Barbón R, Capote A, Pérez N, Jiménez E (2016). In vitro mass propagation of Cymbopogon citratusStapf., a medicinal Gramineae. In: Jain S (Ed). Protocols for in vitro cultures and secondary metabolite analysis of aromatic and medicinal plants, Second Edition. Methods in MolecularBiology. Humana Press, New York, NY.

Ramírez-Mosqueda MA, Iglesias-Andreu LG (2015). Indirect organogenesis and assessment of somaclonal variation in plantlets of Vanilla planifolia Jacks. Plant Cell, Tissue and Organ Culture 123(3):657-664.

SalviND, George L, Eapen S (2001). Plant regeneration from leaf base callus of turmeric and random amplified polymorphic DNA analysis of regenerated plants. Plant Cell, Tissue \& Organ Culture 66(2):113-119.

Sangwan NS, Yadav U, Sangwan RS (2001a). Molecular analysis of genetic diversity in elite Indian cultivars of essential oil trade types of aromatic grasses (Cymbopogon species). Plant Cell Reports 20(5):437-444.

Selim SA (2011). Chemical composition, antioxidant and antimicrobial activity of the essential oil and methanol extract of the Egyptian lemongrass Cymbopogon proximus Stapf. Grasas y Aceites 62(1):55-61.

Semagn K, Bjornstad A, Ndjiondjop MN (2006). An overview of molecular marker methods for plants. African Journal of Biotechnology 5(25):2540-2568.

Shinde S, Sebastian JK, Jain JR, Hanamanthagouda MS, Murthy HN (2016) Efficient in vitro propagation of Artemisia nilagirica var. nilagirica (Indian wormwood) and assessment of genetic fidelity of micropropagated plants. Physiology and Molecular Biology of Plants 22(4):595-603.
Smulders MJM, de Klerk GJ (2011). Epigenetics in plant tissue culture. Plant Growth Regulations63(2):137-146.

Thorat AS, Sonone NA, Choudhari VV, Devarumath RM, Babu KH (2017). Plant regeneration from cell suspension culture in Saccharum officinarum L. and ascertaining of genetic fidelity through RAPD and ISSR markers. 3Biotech 7(1):16.

Tiwari JK, Chandel P, Gupta S, Gopal J, Singh BP, Bhardwaj V (2013). Analysis of genetic stability of in vitro propagated potato micro-tubers using DNA markers. Physiology \& Molecular Biology of Plant 19(4):587-595.

Venetsky AL, Khasdan V, Domb V, Kashkush K (2015). Structure and extent of DNA methylation based epigenetic variation in wild emmer wheat (T. turgidum ssp. dicoccoides) populations. BMC Plant Biology 15(1):1-10.

Walter R, Epperson BK (2004). Microsatellite analysis of spatial structure among seedlings in populations of Pinusstrobus (Pinaceae). American Journal of Botany 91(4):549-557.

Weinhold A (2018). Tran generational stress-adaption: an opportunity for ecological epigenetics. Plant Cell Reports 37(1):3-9. 
Supplementary Files

Table 1. Primer score of ISSR analysis for $\mathrm{W}=$ wild, $\mathrm{SE}=$ Somatic embryogenesis, $\mathrm{D}=$ Direct regeneration and $\mathrm{ID}=$ Indirect regenerated plants. $\mathrm{TAF}=$ Total amplified fragments, $\mathrm{Mb}=$ Monomorphic bands, $\mathrm{Pb}=$ Polymorphic bands

\begin{tabular}{|c|c|c|c|c|c|c|}
\hline Primers & Nucleotide sequence $5^{\prime}-3^{\prime}$ & $\operatorname{Tm}$ & $\begin{array}{c}\text { Band size } \\
(\mathrm{bp})\end{array}$ & TAF & $\mathrm{Mb}$ & $\mathrm{Pb}$ \\
\hline UBC810 & GAGAGAGAGAGAGAGAT & 54.8 & $1921-549$ & 10 & 2 & 8 \\
\hline UBC811 & GAGAGAGAGAGAGAGAC & 57.2 & $1338-510$ & 11 & 0 & 11 \\
\hline UBC819 & GTGTGTGTGTGTGTGTA & 54.8 & $2252-568$ & 9 & 1 & 8 \\
\hline UBC842C & GAGAGAGAGAGAGAGACG & 59.9 & $1883-441$ & 13 & 0 & 13 \\
\hline UBC842T & GAGAGAGAGAGAGAGATG & 57.6 & $2376-451$ & 16 & 1 & 15 \\
\hline UBC846A & CACACACACACACACAAT & 55.3 & $2128-2027$ & 10 & 0 & 10 \\
\hline UBC846G & CACACACACACACACAGT & 57.6 & $1425-441$ & 8 & 2 & 6 \\
\hline UBC849C & GTGTGTGTGTGTGTGTCA & 57.6 & $2000-609$ & 10 & 1 & 9 \\
\hline UBC849T & GTGTGTGTGTGTGTGTTA & 55.3 & $1985-553$ & 12 & 1 & 11 \\
\hline UBC856C & ACACACACACACACACCA & 57.6 & $1682-491$ & 12 & 1 & 11 \\
\hline UBC856T & ACACACACACACACACTA & 55.3 & $1827-429$ & 11 & 2 & 9 \\
\hline UBC857C & ACACACACACACACACCG & 59.9 & $3446-430$ & 16 & 2 & 14 \\
\hline UBC857T & ACACACACACACACACTG & 57.6 & $1761-445$ & 15 & 2 & 13 \\
\hline UBC873 & GACAGACAGACAGACA & 54.2 & $1554-495$ & 11 & 2 & 9 \\
\hline $\mathrm{R}(\mathrm{CA}) 7$ & GCACACACACACACA & 53.4 & $1224-506$ & 9 & 2 & 7 \\
\hline $\mathrm{Y}(\mathrm{TG}) 7$ & CTGTGTGTGTGTGTG & 53.4 & $2257-343$ & 16 & 1 & 15 \\
\hline UBC834T & AGAGAGAGAGAGAGAGTT & 55.3 & $908-200$ & 11 & 2 & 9 \\
\hline UBC860A & TGTGTGTGTGTGTGTGAA & 55.3 & $1738-507$ & 10 & 0 & 10 \\
\hline $\mathrm{CCC}(\mathrm{GT}) 6$ & CCCGTGTGTGTGTGT & 56.2 & $1849-571$ & 12 & 2 & 9 \\
\hline Total & & & & 222 & 24 & 198 \\
\hline
\end{tabular}

Table 2. RAPD analysis of wild plant and in vitro regenerated plants ( $\mathrm{SE}=$ Somatic embryogenesis, $\mathrm{D}=$ Direct regeneration and $\mathrm{ID}=\mathrm{Indirect}$ regeneration) $. \mathrm{TAF}=\mathrm{Total}$ amplified fragments, $\mathrm{Mb}=$ Monomorphic bands, $\mathrm{Pb}=$ Polymorphic bands

\begin{tabular}{|c|c|c|c|c|c|c|}
\hline Primer name & Nucleotide sequence $5^{\prime}-3^{\prime}$ & $\operatorname{Tm}$ & $\begin{array}{c}\text { Band size range } \\
\text { (bp) }\end{array}$ & TAF & $\mathrm{Mb}$ & $\mathrm{Pb}$ \\
\hline OPB-03 & CATCCCCCTG & 43.6 & $1836-324$ & 16 & 0 & 16 \\
\hline OPD-03 & GTCGCCGTCA & 43.6 & $2169-365$ & 16 & 3 & 13 \\
\hline OPD-07 & TTGGCACGGG & 43.6 & $1421-373$ & 15 & 1 & 14 \\
\hline OPC-07 & GTCCCGACGA & 43.6 & $1297-441$ & 7 & 1 & 6 \\
\hline OPE-07 & AGATGCAGCC & 39.5 & $2438-807$ & 10 & 2 & 8 \\
\hline OPI-07 & CAGCGACAAG & 39.5 & $2320-436$ & 9 & 1 & 8 \\
\hline OPK-07 & AGCGAGCAAG & 39.5 & $1146-427$ & 5 & 1 & 4 \\
\hline OPM-07 & CCGTGACTCA & 39.5 & $1377-278$ & 5 & 2 & 3 \\
\hline OPN-07 & CAGCCCAGAG & 43.6 & $1140-362$ & 9 & 1 & 8 \\
\hline OPQ-07 & CCCCGATGGT & 43.6 & $1674-444$ & 11 & 1 & 10 \\
\hline OPR-07 & ACTGGCCTGA & 39.5 & $1907-700$ & 8 & 3 & 5 \\
\hline OPV-07 & GAAGCCAGCC & 43.6 & $1984-500$ & 9 & 2 & 7 \\
\hline OPZ-07 & CCAGGAGGAC & 43.6 & $2275-523$ & 12 & 4 & 8 \\
\hline OPAC-07 & GTGGCCGATG & 43.6 & $1018-625$ & 7 & 2 & 5 \\
\hline Total & & & & 139 & 24 & 115 \\
\hline
\end{tabular}

Table 3. cpSSR marker analysis of wild plant and in vitro regenerated plants ( $\mathrm{SE}=$ Somatic embryogenesis, $\mathrm{D}=\mathrm{Direct}$ regeneration and $\mathrm{ID}=\mathrm{Indirect}$ regeneration).TAF= Total amplified fragments, $\mathrm{Mb}=$ Monomorphic bands, $\mathrm{Pb}=\mathrm{Polymorphic} \mathrm{band} s$

\begin{tabular}{|c|c|c|c|c|c|c|}
\hline Primer name & Nucleotide sequence $5^{\prime}-3^{\prime}$ & $\operatorname{Tm}$ & $\begin{array}{l}\text { Band size range } \\
\text { (bp) }\end{array}$ & TAF & $\mathrm{Mb}$ & $\mathrm{Pb}$ \\
\hline VgcpSSR5-F & AGCCCACTTTTCCGTAGGTT & \multirow{2}{*}{60.4} & \multirow[t]{2}{*}{$967-902$} & \multirow{2}{*}{1} & \multirow{2}{*}{1} & \multirow{2}{*}{0} \\
\hline VgcpSSR5-R & СTTTTCCTTGCCATAATGGTT & & & & & \\
\hline CCMP1-F & CAGGTAAACTTCTCAACGGA & \multirow{2}{*}{58.4} & \multirow[b]{2}{*}{$8486-773$} & \multirow[b]{2}{*}{11} & \multirow[b]{2}{*}{0} & \multirow[b]{2}{*}{11} \\
\hline CCMP1-R & CCGAAGTCAAAAGAGCGATT & & & & & \\
\hline CCMP2-F & GATCCCGGACGTAATCCTG & \multirow{2}{*}{62.3} & \multirow[b]{2}{*}{$8206-764$} & \multirow[b]{2}{*}{11} & \multirow[b]{2}{*}{1} & \multirow[b]{2}{*}{10} \\
\hline CCMP2-R & ATCGTACCGAGGGTTCGAAT & & & & & \\
\hline $\operatorname{trnK}$ intron-F & ATACAGTCTCTTTATCAATATACTG & \multirow{2}{*}{56.4} & \multirow{2}{*}{$154-37$} & \multirow[b]{2}{*}{2} & \multirow{2}{*}{1} & \multirow[b]{2}{*}{1} \\
\hline trnK intron- $\mathrm{R}$ & GACGTTAAAAATAGATTAGTGCC & & & & & \\
\hline psbK-psbI-F & GGAAAAAYKGGTAATCTATTCC & \multirow{2}{*}{57.1} & \multirow[t]{2}{*}{$127-153$} & \multirow{2}{*}{1} & \multirow{2}{*}{1} & \multirow{2}{*}{0} \\
\hline psbK-psbI-R & GAAACAAAGAATATCACTACTG & & & & & \\
\hline rpoC2-rps2-F & TTATTTATTTCAAGCTATTTCGG & \multirow{2}{*}{53.9} & \multirow[t]{2}{*}{$134-123$} & \multirow{2}{*}{1} & \multirow{2}{*}{1} & \multirow{2}{*}{0} \\
\hline rpoC2-rps2-R & АATATCTTCTTGTCATTTTTTCC & & & & & \\
\hline atpI-atpH-F & TGGTTGATTGTATCCTTAACC & \multirow{3}{*}{56.7} & \multirow{3}{*}{$445-58$} & \multirow[b]{2}{*}{2} & \multirow[b]{2}{*}{1} & \multirow[b]{2}{*}{1} \\
\hline atpI-atpH-R & GAAGCAGCAGCAATTAGTGG & & & & & \\
\hline Total & & & & 29 & 6 & 23 \\
\hline
\end{tabular}


Supplementary Files

Table 4. Jaccard's similarity coefficient based on ISSR analysis of the in vitro regenerated plants through SE=Somatic embryogenesis, D=Direct organogenesis, ID=Indirect organogenesis and $\mathrm{W}=$ wild

\begin{tabular}{|c|c|c|c|c|c|c|c|c|c|c|c|c|c|c|c|c|c|c|}
\hline 0 & W1 & W2 & W3 & SE 1 & SE 2 & SE 3 & SE 4 & SE 5 & $\mathrm{D} 1$ & D2 & D3 & D4 & D5 & ID1 & ID2 & ID3 & ID4 & ID5 \\
\hline W1 & 1 & & & & & & & & & & & & & & & & & \\
\hline W2 & 0.69 & 1 & & & & & & & & & & & & & & & & \\
\hline W3 & 0.50 & 0.57 & 1 & & & & & & & & & & & & & & & \\
\hline SE 1 & 0.46 & 0.50 & 0.45 & 1 & & & & & & & & & & & & & & \\
\hline SE 2 & 0.47 & 0.49 & 0.42 & 0.80 & 1 & & & & & & & & & & & & & \\
\hline SE 3 & 0.47 & 0.46 & 0.40 & 0.62 & 0.63 & 1 & & & & & & & & & & & & \\
\hline SE 4 & 0.47 & 0.47 & 0.36 & 0.59 & 0.63 & 0.73 & 1 & & & & & & & & & & & \\
\hline SE 5 & 0.47 & 0.45 & 0.39 & 0.52 & 0.56 & 0.67 & 0.64 & 1 & & & & & & & & & & \\
\hline D1 & 0.39 & 0.43 & 0.36 & 0.43 & 0.44 & 0.47 & 0.47 & 0.46 & 1 & & & & & & & & & \\
\hline D2 & 0.39 & 0.44 & 0.37 & 0.44 & 0.46 & 0.48 & 0.49 & 0.45 & 0.86 & 1 & & & & & & & & \\
\hline D3 & 0.39 & 0.41 & 0.38 & 0.44 & 0.45 & 0.51 & 0.47 & 0.48 & 0.73 & 0.79 & 1 & & & & & & & \\
\hline D4 & 0.38 & 0.42 & 0.38 & 0.43 & 0.45 & 0.47 & 0.44 & 0.46 & 0.70 & 0.75 & 0.74 & 1 & & & & & & \\
\hline D5 & 0.39 & 0.42 & 0.35 & 0.40 & 0.40 & 0.42 & 0.45 & 0.42 & 0.61 & 0.66 & 0.66 & 0.70 & 1 & & & & & \\
\hline ID1 & 0.33 & 0.36 & 0.33 & 0.36 & 0.33 & 0.36 & 0.41 & 0.38 & 0.47 & 0.46 & 0.46 & 0.48 & 0.48 & 1 & & & & \\
\hline ID2 & 0.34 & 0.36 & 0.32 & 0.33 & 0.30 & 0.33 & 0.35 & 0.37 & 0.38 & 0.36 & 0.39 & 0.39 & 0.40 & 0.72 & 1 & & & \\
\hline ID3 & 0.35 & 0.34 & 0.35 & 0.31 & 0.28 & 0.34 & 0.34 & 0.36 & 0.38 & 0.37 & 0.39 & 0.42 & 0.42 & 0.66 & 0.80 & 1 & & \\
\hline ID 4 & 0.34 & 0.33 & 0.331 & 0.30 & 0.30 & 0.33 & 0.34 & 0.34 & 0.41 & 0.40 & 0.39 & 0.43 & 0.43 & 0.60 & 0.67 & 0.75 & 1 & \\
\hline ID5 & 0.34 & 0.35 & 0.321 & 0.33 & 0.32 & 0.33 & 0.35 & 0.36 & 0.40 & 0.40 & 0.37 & 0.40 & 0.42 & 0.60 & 0.68 & 0.70 & 0.78 & 1 \\
\hline
\end{tabular}

Table 5. Jaccard's similarity coefficient based RAPD data of the in vitro propagated shoots through SE=Somatic embryogenesis, D=Direct organogenesis, $\mathrm{ID}=$ =Indirect organogenesis and $\mathrm{W}=$ wild plant

\begin{tabular}{|c|c|c|c|c|c|c|c|c|c|c|c|c|c|c|c|c|c|c|}
\hline 0 & W1 & W2 & W3 & SE 1 & SE 2 & SE 3 & SE 4 & SE 5 & D1 & D2 & D3 & D4 & D5 & ID1 & ID2 & ID3 & ID4 & ID5 \\
\hline W1 & 1 & & & & & & & & & & & & & & & & & \\
\hline W2 & 0.81 & 1 & & & & & & & & & & & & & & & & \\
\hline W3 & 0.70 & 0.72 & 1 & & & & & & & & & & & & & & & \\
\hline SE1 & 0.52 & 0.54 & 0.64 & 1 & & & & & & & & & & & & & & \\
\hline SE2 & 0.58 & 0.59 & 0.62 & 0.84 & 1 & & & & & & & & & & & & & \\
\hline SE3 & 0.52 & 0.56 & 0.54 & 0.77 & 0.83 & 1 & & & & & & & & & & & & \\
\hline SE4 & 0.53 & 0.56 & 0.57 & 0.71 & 0.73 & 0.78 & 1 & & & & & & & & & & & \\
\hline SE5 & 0.49 & 0.55 & 0.52 & 0.69 & 0.72 & 0.82 & 0.87 & 1 & & & & & & & & & & \\
\hline D1 & 0.45 & 0.42 & 0.41 & 0.39 & 0.43 & 0.45 & 0.49 & 0.48 & 1 & & & & & & & & & \\
\hline D2 & 0.44 & 0.41 & 0.43 & 0.36 & 0.36 & 0.39 & 0.42 & 0.42 & 0.81 & 1 & & & & & & & & \\
\hline D3 & 0.44 & 0.44 & 0.44 & 0.40 & 0.40 & 0.43 & 0.43 & 0.44 & 0.80 & 0.89 & 1 & & & & & & & \\
\hline D4 & 0.46 & 0.46 & 0.45 & 0.39 & 0.42 & 0.44 & 0.46 & 0.45 & 0.815 & 0.85 & 0.94 & 1 & & & & & & \\
\hline D5 & 0.43 & 0.43 & 0.42 & 0.38 & 0.40 & 0.42 & 0.44 & 0.43 & 0.79 & 0.83 & 0.86 & 0.90 & 1 & & & & & \\
\hline ID1 & 0.50 & 0.53 & 0.50 & 0.54 & 0.59 & 0.56 & 0.63 & 0.63 & 0.56 & 0.48 & 0.49 & 0.50 & 0.53 & 1 & & & & \\
\hline ID2 & 0.48 & 0.53 & 0.49 & 0.53 & 0.53 & 0.54 & 0.59 & 0.63 & 0.53 & 0.50 & 0.52 & 0.53 & 0.54 & 0.80 & 1 & & & \\
\hline ID3 & 0.46 & 0.49 & 0.48 & 0.52 & 0.51 & 0.52 & 0.56 & 0.60 & 0.56 & 0.50 & 0.53 & 0.54 & 0.55 & 0.71 & 0.78 & 1 & & \\
\hline ID4 & 0.49 & 0.52 & 0.55 & 0.54 & 0.52 & 0.52 & 0.58 & 0.60 & 0.60 & 0.55 & 0.57 & 0.58 & 0.57 & 0.71 & 0.72 & 0.79 & 1 & \\
\hline ID5 & 0.47 & 0.50 & 0.51 & 0.47 & 0.48 & 0.50 & 0.57 & 0.56 & 0.59 & 0.57 & 0.54 & 0.55 & 0.55 & 0.72 & 0.70 & 0.77 & 0.84 & 1 \\
\hline
\end{tabular}


Abdelsalam AM et al / Not Sci Biol, 2019, 11(2):222-232

Supplementary Files

Table 6. Jaccard's similarity coefficient based on cpSSR dataof the in vitro propagated shoots through $\mathrm{SE}=\mathrm{Somatic}$ embryogenesis, $\mathrm{D}=\mathrm{Direct}$ organogenesis, ID=Indirect organogenesis and $\mathrm{W}=$ =wild plant

\begin{tabular}{|c|c|c|c|c|c|c|c|c|c|c|c|c|c|c|c|c|c|c|c|c|c|c|}
\hline 0 & W1 & W2 & W3 & W4 & SE 1 & SE 2 & SE 3 & SE 4 & SE 5 & SE 6 & ID1 & ID2 & ID3 & ID4 & ID5 & ID6 & D1 & D2 & D3 & D4 & D5 & D6 \\
\hline W1 & 1 & & & & & & & & & & & & & & & & & & & & & \\
\hline W2 & 0.80 & 1 & & & & & & & & & & & & & & & & & & & & \\
\hline W3 & 0.69 & 0.55 & 1 & & & & & & & & & & & & & & & & & & & \\
\hline W4 & 0.56 & 0.71 & 0.71 & 1 & & & & & & & & & & & & & & & & & & \\
\hline SE 1 & 0.61 & 0.67 & 0.50 & 0.55 & 1 & & & & & & & & & & & & & & & & & \\
\hline SE 2 & 0.44 & 0.42 & 0.42 & 0.40 & 0.71 & 1 & & & & & & & & & & & & & & & & \\
\hline SE 3 & 0.53 & 0.50 & 0.42 & 0.40 & 0.81 & 0.86 & 1 & & & & & & & & & & & & & & & \\
\hline SE 4 & 0.39 & 0.37 & 0.37 & 0.35 & 0.65 & 0.92 & 0.79 & 1 & & & & & & & & & & & & & & \\
\hline SE 5 & 0.47 & 0.44 & 0.37 & 0.35 & 0.75 & 0.77 & 0.92 & 0.85 & 1 & & & & & & & & & & & & & \\
\hline SE 6 & 0.56 & 0.61 & 0.45 & 0.50 & 0.94 & 0.65 & 0.75 & 0.69 & 0.80 & 1 & & & & & & & & & & & & \\
\hline ID1 & 0.30 & 0.29 & 0.35 & 0.33 & 0.38 & 0.44 & 0.44 & 0.47 & 0.47 & 0.40 & 1 & & & & & & & & & & & \\
\hline ID2 & 0.35 & 0.33 & 0.40 & 0.38 & 0.43 & 0.42 & 0.42 & 0.44 & 0.44 & 0.45 & 0.69 & 1 & & & & & & & & & & \\
\hline ID3 & 0.40 & 0.38 & 0.45 & 0.43 & 0.48 & 0.40 & 0.40 & 0.42 & 0.42 & 0.50 & 0.65 & 0.71 & 1 & & & & & & & & & \\
\hline ID4 & 0.38 & 0.36 & 0.43 & 0.41 & 0.46 & 0.38 & 0.38 & 0.40 & 0.40 & 0.48 & 0.61 & 0.88 & 0.82 & 1 & & & & & & & & \\
\hline ID5 & 0.37 & 0.35 & 0.42 & 0.40 & 0.45 & 0.44 & 0.44 & 0.47 & 0.47 & 0.47 & 0.73 & 0.80 & 0.87 & 0.71 & 1 & & & & & & & \\
\hline ID6 & 0.29 & 0.27 & 0.33 & 0.32 & 0.36 & 0.42 & 0.42 & 0.44 & 0.44 & 0.38 & 0.93 & 0.75 & 0.71 & 0.67 & 0.80 & 1 & & & & & & \\
\hline D1 & 0.40 & 0.38 & 0.53 & 0.43 & 0.41 & 0.40 & 0.40 & 0.35 & 0.35 & 0.36 & 0.56 & 0.45 & 0.43 & 0.48 & 0.40 & 0.53 & 1 & & & & & \\
\hline D2 & 0.44 & 0.42 & 0.42 & 0.40 & 0.45 & 0.44 & 0.44 & 0.39 & 0.39 & 0.40 & 0.30 & 0.35 & 0.40 & 0.38 & 0.37 & 0.35 & 0.56 & 1 & & & & \\
\hline D3 & 0.47 & 0.44 & 0.44 & 0.42 & 0.47 & 0.47 & 0.47 & 0.41 & 0.41 & 0.42 & 0.32 & 0.37 & 0.42 & 0.40 & 0.39 & 0.37 & 0.59 & 0.92 & 1 & & & \\
\hline D4 & 0.44 & 0.42 & 0.50 & 0.47 & 0.53 & 0.53 & 0.53 & 0.47 & 0.47 & 0.47 & 0.37 & 0.42 & 0.47 & 0.45 & 0.44 & 0.42 & 0.65 & 0.86 & 0.92 & 1 & & \\
\hline D5 & 0.47 & 0.44 & 0.44 & 0.42 & 0.47 & 0.47 & 0.47 & 0.41 & 0.41 & 0.42 & 0.32 & 0.37 & 0.42 & 0.40 & 0.39 & 0.37 & 0.50 & 0.92 & 0.85 & 0.79 & 1 & \\
\hline D6 & 0.40 & 0.38 & 0.53 & 0.43 & 0.41 & 0.40 & 0.40 & 0.35 & 0.35 & 0.36 & 0.56 & 0.53 & 0.50 & 0.55 & 0.47 & 0.61 & 0.88 & 0.56 & 0.59 & 0.65 & 0.59 & 1 \\
\hline
\end{tabular}

Table 7. List of ISSR primers used in the present study with their nucleotide sequence and references

\begin{tabular}{|c|c|c|}
\hline Primer ID & Nucleotide sequence 5'-3' & Reference \\
\hline UBC810 & GAGAGAGAGAGAGAGAT & Melo et al., 2011 \\
\hline UBC811 & GAGAGAGAGAGAGAGAC & Zhu et al., 2011 \\
\hline UBC819 & GTGTGTGTGTGTGTGTA & Zhu et al., 2011 \\
\hline UBC842C & GAGAGAGAGAGAGAGACG & Zhu et al., 2011 \\
\hline UBC842T & GAGAGAGAGAGAGAGATG & Zhu et al., 2011 \\
\hline UBC846A & CACACACACACACACAAT & Zhu et al., 2011 \\
\hline UBC846G & CACACACACACACACAGT & Zhu et al., 2011 \\
\hline UBC849C & GTGTGTGTGTGTGTGTCA & Zhu et al., 2011 \\
\hline UBC849T & GTGTGTGTGTGTGTGTTA & Zhu et al., 2011 \\
\hline UBC856C & ACACACACACACACACCA & Zhu et al., 2011 \\
\hline UBC856T & ACACACACACACACACTA & Zhu et al., 2011 \\
\hline UBC857C & ACACACACACACACACCG & Zhu et al., 2011 \\
\hline UBC857T & ACACACACACACACACTG & Zhu et al., 2011 \\
\hline UBC861 & ACCACCACCACCACCACC & Melo et al., 2011 \\
\hline UBC862 & AGCAGCAGCAGCAGCAGC & Melo et al., 2011 \\
\hline UBC873 & GACAGACAGACAGACA & Melo et al, 2011 \\
\hline $\mathrm{R}(\mathrm{CA}) 7$ & GCACACACACACACA & Melo et al., 2011 \\
\hline $\mathrm{Y}(\mathrm{TG}) 7$ & CTGTGTGTGTGTGTG & Melo et al., 2011 \\
\hline $\mathrm{TA}(\mathrm{CAG}) 4$ & TACAGCAGCAGCAG & Melo et al., 2011 \\
\hline CRR(ATT) 4 & CAGATTATTATTATT & Melo et al., 2011 \\
\hline $\mathrm{RA}(\mathrm{GCT}) 6$ & AAGCTGCTGCTGCTGCTGCT & Melo et al., 2011 \\
\hline UBC827 & ACACACACACACACACG & Morales et al., 2011 \\
\hline UBC834C & AGAGAGAGAGAGAGAGCT & Morales et al., 2011 \\
\hline UBC834T & AGAGAGAGAGAGAGAGTT & Morales et al., 2011 \\
\hline UBC845A & СТСТСТСТСТСТСТCTAG & Morales et al., 2011 \\
\hline UBC845G & СтCTCTCTCTCTCTCTGG & Morales et al., 2011 \\
\hline UBC848A & CACACACACACACACAAG & Morales et al., 2011 \\
\hline UBC848G & CACACACACACACACAGG & Morales et al., 2011 \\
\hline UBC860A & TGTGTGTGTGTGTGTGAA & Morales et al., 2011 \\
\hline UBC860G & TGTGTGTGTGTGTGTGGA & Morales et al., 2011 \\
\hline (AC) $8 \mathrm{TG}$ & ACACACACACACACACTC & $\mathrm{Li}$ and Ge, 2001 \\
\hline$(\mathrm{AC}) 8 \mathrm{TC}$ & ACACACACACACACACCC & Li and Ge, 2001 \\
\hline $\mathrm{CCC}(\mathrm{GT}) 6$ & CCCGTGTGTGTGTGT & Li and Ge, 2001 \\
\hline $\mathrm{GCG}(\mathrm{AC}) 6 \mathrm{~A}$ & GCGACACACACACACA & Li and Ge, 2001 \\
\hline $\mathrm{CA}(\mathrm{GA}) 8$ & CAGAGAGAGAGAGAGAGA & Costa et al., 2011 \\
\hline $\mathrm{GC}(\mathrm{GA}) 8$ & GCGAGAGAGAGAGAGAGA & Costa et al., 2011 \\
\hline$(\mathrm{GCT}) 5 \mathrm{C}$ & GCTGCTGCTGCTGCTC & Costa et al., 2011 \\
\hline$(\mathrm{GCT}) 5 \mathrm{~T}$ & GCTGCTGCTGCTGCTT & Costa et al., 2011 \\
\hline$(\mathrm{AGC}) 5 \mathrm{GR}$ & AGCAGCAGCAGCAGCA & Costa et al., 2011 \\
\hline (AGC)5GR & AGCAGCAGCAGCAGCG & Costa et al., 2011 \\
\hline$(\mathrm{GAC}) 5$ & GACGACGACGACGAC & Shi et al., 2010 \\
\hline (GTG)5 & GTGGTGGTGGTGGTG & Shi et al., 2010 \\
\hline (TGTC) 5 & TGTCTGTCTGTCTGTCTGTC & Shi et al., 2010 \\
\hline$($ GTGTGG)3 & GTGTGGGTGTGGGTGTGG & Shi et al., 2010 \\
\hline
\end{tabular}


Abdelsalam AM et al / Not Sci Biol, 2019, 11(2):222-232

Supplementary Files

Table 8. List of cpSSR primers screened with their nucleotide sequence and references

\begin{tabular}{|c|c|c|}
\hline Primer ID & Primer Nucleotide Sequences $\left(5^{\prime}-3^{\prime}\right)$ & References \\
\hline VgcpSSR1-F & GGTGGATGTTTATACCCAATCG & Pan et al., 2014 \\
\hline VgcpSSR1-R & TCTTTCTGCGATACAAACAAGAA & \\
\hline VgcpSSR2-F & TTTTCTATGTATGGCGCAACC & Pan et al., 2014 \\
\hline VgcpSSR2-R & CGGGGATAAAGCTGCCTATT & \\
\hline VgcpSSR3-F & AAACCACTCGAATATTATGGAAA & Pan et al., 2014 \\
\hline VgcpSSR3-R & CCAGTTCAAATCTGGTTCCTG & \\
\hline VgcpSSR4-F & GAAAAGAACAAGCAAATCCACA & Pan et al., 2014 \\
\hline VgcpSSR4-R & TGATCCTTACGATGCTTCCTTT & \\
\hline VgcpSSR5-F & AGCCCACTTTTCCGTAGGTT & Pan et al., 2014 \\
\hline VgcpSSR5-R & СТTTTCCTTGCCATAATGGTT & \\
\hline VgcpSSR7-F & TCAАССАТТТСССААСАССТ & Pan et al., 2014 \\
\hline VgcpSSR7-R & CATCGAGTTCATGGATTTGC & \\
\hline VgcpSSR9-F & TGAAATTTGAAAAACGGGGTA & Pan et al., 2014 \\
\hline VgcpSSR9-R & AAGCGATACGGATAGATTCCT & \\
\hline VgcpSSR10-F & GGGCTCATTGGCTGTAGAAA & Pan et al., 2014 \\
\hline VgcpSSR10-R & ССАТСТСТССССААТTGAAA & \\
\hline VgcpSSR11-F & TTTGAGAAGGTTCAATTGTTCG & Pan et al., 2014 \\
\hline VgcpSSR11-R & TCGGACTCTAGGAAAGGACAA & \\
\hline VgcpSSR12-F & GGCCATTTATCCСАСТTTCC & Pan et al., 2014 \\
\hline VgcpSSR12-R & CCAGTCTCTACTGGGGGTTA & \\
\hline VgcpSSR13-F & TATTGGTTTTGCACCAATCG & Pan et al., 2014 \\
\hline VgcpSSR13-R & ACCAGGGTGTATGTGCGACT & \\
\hline VgcpSSR14-F & TGGATCATAATCCTTGAACATCA & Pan et al., 2014 \\
\hline VgcpSSR14-R & TGCGAAAACAAAGATAAGAAATCA & \\
\hline CCMP1-F & CAGGTAAACTTCTCAACGGA & Weis and Gard, 1999 \\
\hline CCMP1-R & CCGAAGTCAAAAGAGCGATT & \\
\hline CCMP2-F & GATCCCGGACGTAATCCTG & Weis and Gard, 1999 \\
\hline CCMP2-R & ATCGTACCGAGGGTTCGAAT & \\
\hline CCMP3-F & CAGACCAAAAGCTGACATAG & \\
\hline CCMP3-R & GTTTCATTCGGCTCCTTTAT & Weis and Gard, 1999 \\
\hline CCMP4-F & AATGCTGAATCGAYGACCTA & \\
\hline CCMP4-R & CCAAAATATTBGGAGGACTCT & Weis and Gard, 1999 \\
\hline CCMP5-F & TGTTCCAATATCTTCTTGTCATTT & Weis and Gard, 1999 \\
\hline CCMP5-R & AGGTTCCATCGGAACAATTAT & \\
\hline CCMP6-F & CGATGCATATGTAGAAAGCC & Weis and Gard, 1999 \\
\hline CCMP6-R & CATTACGTGCGACTATCTCC & \\
\hline CCMP7-F & CAACATATACCACTGTCAAG & Weis and Gard, 1999 \\
\hline CCMP7-R & ACATCATTATTGTATACTCTTTC & \\
\hline CCMP8-F & TTGGCTACTCTAACCTTCCC & Weis and Gard, 1999 \\
\hline CCMP8-R & TTCTTTCTTATTTCGCAGDGAA & \\
\hline CCMP9-F & GGATTTGTACATATAGGACA & Weis and Gard, 1999 \\
\hline CCMP9-R & СТCAACTCTAAGAAATACTTG & \\
\hline CCMP10-F & TTTTTTTTTAGTGAACGTGTCA & Weis and Gard, 1999 \\
\hline CCMP10-R & TTCGTCGDCGTAGTAAATAG & \\
\hline CSU01-F & TTCCCGATTCTACTAGCACTC & Peng and Chen, 2011 \\
\hline CSU01-R & ATTATTATCGCTGGTGCAGAG & \\
\hline CSU03-F & AAAGTATTCCTGACCCAATCG & Peng and Chen, 2011 \\
\hline CSU03-R & ACTAGGACTTATCTTTATCGC & \\
\hline CSU05-F & TGTTCGATAGCAAGTTGATTG & Peng and Chen, 2011 \\
\hline CSU05-R & GAGTTAGTTGAACTTATCACTC & \\
\hline CSU07-F & GACTTTCTACTTACAAATCCTG & Peng and Chen, 2011 \\
\hline CSU07-R & ATAATTCACTGATCCACCATG & \\
\hline $\operatorname{trnK}$ intron- $\mathrm{F}$ & ATACAGTCTCTTTATCAATATACTG & Provan et al., 2004 \\
\hline $\operatorname{trnK}$ intron- $\mathrm{R}$ & GACGTTAAAAATAGATTAGTGCC & \\
\hline psbK-psbI-F & GGAAAAAYKGGTAATCTATTCC & Provan et al., 2004 \\
\hline psbK-psbI-R & GAAACAAAGAATATCACTACTG & \\
\hline rpoC2-rps2-F & TTATTTATTTCAAGCTATTTCGG & Provan et al., 2004 \\
\hline rpoC2-rps2-R & AATATCTTCTTGTCATTTTTTCC & \\
\hline atpI-atpH-F & TGGTTGATTGTATCCTTAACC & Provan et al., 2004 \\
\hline atpI-atpH-R & GAAGCAGCAGCAATTAGTGG & \\
\hline
\end{tabular}


Abdelsalam AM et al / Not Sci Biol, 2019, 11(2):222-232

\begin{tabular}{|c|c|c|}
\hline atpB-rbcL-F & GATTGGTTCTCATAATTATCAC & Provan et al., 2004 \\
\hline atpB-rbcL-R & TATTGAATTAACTAATTCATTTCC & \\
\hline NTCP T10-F & CTTCCAAGCTAACGATGC & Provan et al., 2004 \\
\hline NTCP T10-R & СТGTCСТАТССАTTAGACAATG & \\
\hline NTCP T12-F & ССТССАТСАТСТСТТССАА & Provan et al., 2004 \\
\hline NTCP T12-R & ATTTATTTCAGTTCAGGGTTCC & \\
\hline NTCP T18-F & CTGTTCTTTCCATGACСССТC & Provan et al., 2004 \\
\hline NTCP T18-R & CCACCTAGCCAAGCCAGA & \\
\hline NTCP T40-F & GATGTAGCCAAGTGGATCA & Provan et al., 2004 \\
\hline NTCP T40-R & TAATTTGATTCTTCGTCGC & \\
\hline Rc3-F & TAGGCATAATTCCCAACCCA & Provan et al., 2004 \\
\hline Rc3-R & СTTATCCATTTGGAGCATAGGG & \\
\hline Rc5-F & ATTTGGAATTTGGACATTTTGG & Provan et al., 2004 \\
\hline Rc5-R & ACTGATTCGTAGGCGTGGAC & \\
\hline Rc6-F & GAATTTTAGAACTTTGAATTTTTTACCC & Provan et al., 2004 \\
\hline Rc6-R & AAGCGTACCGAAGACTCGAA & \\
\hline Rc9-F & ATAAGGTTATTCCCCGCTTACC & Provan et al., 2004 \\
\hline Rc9-R & AAATTGGGGGAATTCGTACC & \\
\hline ARCP1-F & GAACGACGGGAATTGAACC & Cheng et al., 2006 \\
\hline ARCP1-R & GGTGGAATTTGCTACCTTTTT & \\
\hline ARCP2-F & TGGAGAAGGTTCTTTTTCAAGC & Cheng et al., 2006 \\
\hline ARCP2-R & CGAACCCTCGGTACGATTAA & \\
\hline ARCP4-F & CAATTCGGGATTTTCCTTGA & Cheng et al., 2006 \\
\hline ARCP4-R & GAGCGAAGGGGTACGAAATA & \\
\hline ARCP5-F & GGCCATAGGCTGGAAAGTCT & Cheng et al., 2006 \\
\hline ARCP5-R & GTTTATGCATGGCGAAAAGG & \\
\hline ARCP7-F & TTTACCGAGCAGGTCTACG & Cheng et al., 2006 \\
\hline ARCP7-R & TGAACGATCCCCAGGACTTA & \\
\hline ARCP9-F & GAAAAATGCAAGCACGGTTT & Cheng et al., 2006 \\
\hline ARCP9-R & TACGATCCGTAGTGGGTTGC & \\
\hline ARCP11-F & GAGCGAAGGGGTACGAAATA & Cheng et al., 2006 \\
\hline ARCP11-R & CAATTCGGGATTTTCCTTGA & \\
\hline $\operatorname{ccSSR} 5-\mathrm{F}$ & GGTGCCATTTTAGGATTCCA & Cheng et al., 2006 \\
\hline $\operatorname{ccSSR} 5-\mathrm{R}$ & GAGAAGGTTCCATCGGAACAA & \\
\hline $\operatorname{ccSSR} 12-\mathrm{F}$ & GCTTTGGTATCTTTCGCCTCT & Cheng et al., 2006 \\
\hline ccSSR12-R & TCCATAGATTCGATCGTGGTT & \\
\hline $\operatorname{ccSSR} 21-\mathrm{F}$ & AGCCATTTCATTTCGGGTTA & Cheng et al., 2006 \\
\hline $\operatorname{ccSSR} 21-\mathrm{R}$ & ACGCCAGGATGATAAAAAGC & \\
\hline
\end{tabular}

